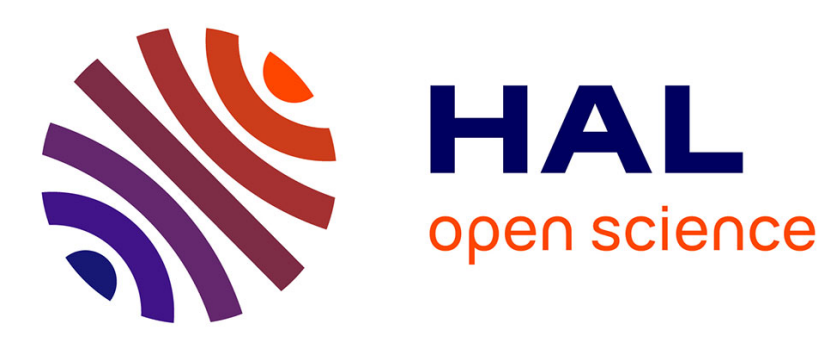

\title{
Do actuaries believe in longevity deceleration?
}

Edouard Debonneuil, Stéphane Loisel, Frédéric Planchet

\section{To cite this version:}

Edouard Debonneuil, Stéphane Loisel, Frédéric Planchet. Do actuaries believe in longevity deceleration?. 2015. hal-01219270v2

\section{HAL Id: hal-01219270 \\ https://hal.science/hal-01219270v2}

Preprint submitted on 5 Aug 2017

HAL is a multi-disciplinary open access archive for the deposit and dissemination of scientific research documents, whether they are published or not. The documents may come from teaching and research institutions in France or abroad, or from public or private research centers.
L'archive ouverte pluridisciplinaire HAL, est destinée au dépôt et à la diffusion de documents scientifiques de niveau recherche, publiés ou non, émanant des établissements d'enseignement et de recherche français ou étrangers, des laboratoires publics ou privés. 


\title{
DO ACTUARIES BELIEVE IN LONGEVITY DECELERATION?
}

\author{
Edouard Debonneuil $^{\alpha} \quad$ Stéphane Loisel* ${ }^{*} \quad$ Frédéric Planchet $^{*}$ \\ Univ Lyon - Université Claude Bernard Lyon 1, \\ ISFA, Laboratoire SAF EA2429, F-69366, Lyon, France \\ Prim'Act, 42 avenue de la Grande Armée, 75017 Paris, France \\ ActuRx
}

Version 2.0 du 05/08/2017

\begin{abstract}
As more and more people believe that significant life extensions may come soon, should commonly used future mortality assumptions be considered prudent? We find here that commonly used actuarial tables for annuitants - as well as the Lee-Carter model - do not extrapolate life expectancy at the same rate for future years as for past years; instead they produce some longevity deceleration. This is typically because their mortality improvements decrease after a certain age, and those age-specific improvements are constant over time. As potential alternatives i) we study the Bongaarts model that produces straight increases in life expectancy; ii) we adapt it to produce best-practice longevity trends iii) we compare with various longevity scenarios even including a model for "life extension velocity". iv) after gathering advances in biogerontology we discuss elements to help retirement systems cope with a potential strong increase in life expectancy.
\end{abstract}

\section{Sommaire}

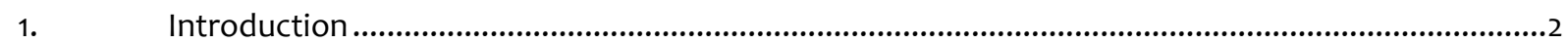

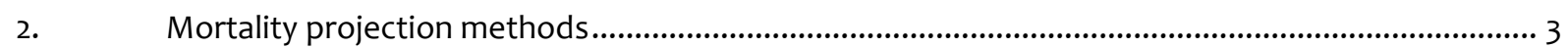

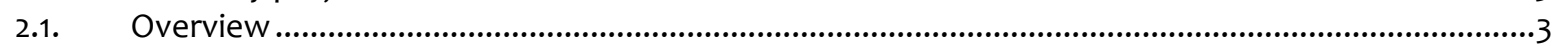

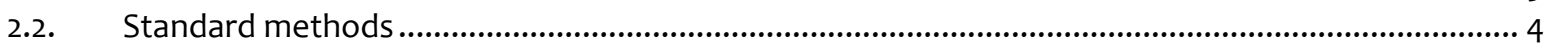

2.3. Best practice trend model....................................................................................................... 5

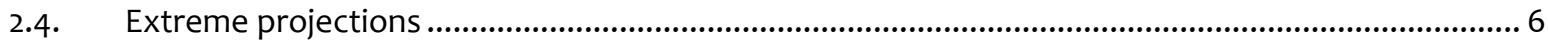

3. Commonly used mortality tables produce decelerating life expectancies ......................................... 6

3.1. Decelerating common actuarial tables, by country ........................................................................... 6

3.2. Why do common actuarial tables and models produce life expectancy deceleration, mathematically speaking? ............................................................................................................................... 13

3.3. A retrospective analysis argues for non-decelerating, non-extrapolative trends ............................ 17

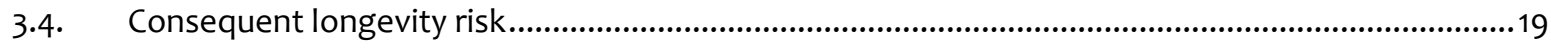

4. Dealing with the risk of extreme longevity ......................................................................................... 21

4.1. Longevity risk with regards to other scenarios of future longevity .................................................. 21

4.2. How serious is biogerontology about strong life extensions? .............................................................22

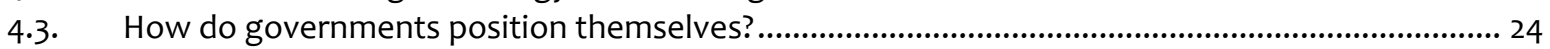

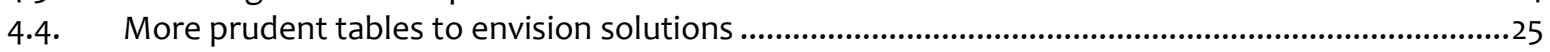

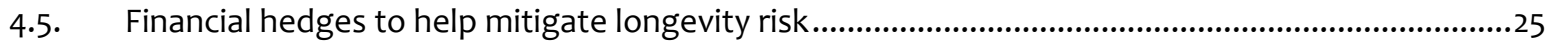

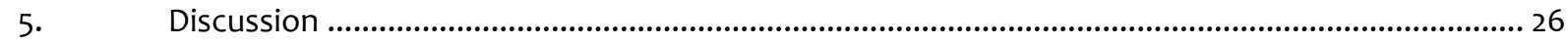

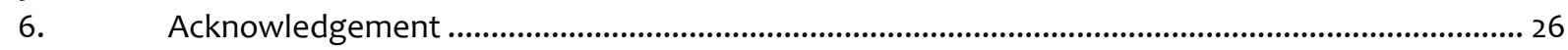

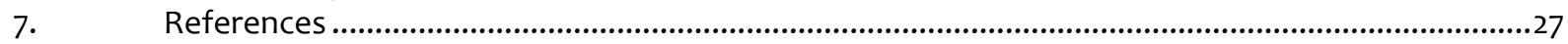

${ }^{\alpha}$ Edouard Debonneuil is founder of ActuRx. Contact: edebonneuil@yahoo.fr

* Stéphane Loisel and Frédéric Planchet are researcher at SAF laboratory (EA n²429). Frédéric Planchet is also consulting actuary at Prim'Act. Contact: stephane.loisel@univ-lyon1.fr / frederic@planchet.net. Their work benefited partially from the financial support of the ANR project "LoLitA" (ANR-13-BS01-0011). 


\section{INTRODUCTION}

During an online interview with more than 200 attendants, the bio gerontologist Aubrey de Grey indicated that he estimates at $60 \%$ the probability that people currently aged 40 reach "Longevity Escape Velocity" (de Grey, 2015), a set of scenarios where one's remaining life expectancy increases as one ages, because therapies gradually come to restore health faster than the rate of body deterioration due to biological aging (de Grey, 2010). There is so far evidence of strong life expectancy improvements in animal models (see for example Bartke et al. 2008 or Bernardes de Jesus et al. 2012) but little (Bannister at al. 2014) or no evidence of such medical advances in humans so far. We are still far from curing some diseases where one single gene is the source of the problem. Therefore, it may take longer than de Grey's estimate to strongly slow or reverse ageing. Besides, one would need to think more about the social and economical issues that would appear in such a world and about their negative impacts on longevity improvements. Nevertheless, given the increasing number of scientists who believe that the human lifespan may soon increase at an unprecedented pace, one may wonder if retirement systems are built in a way that could cope with such scenarios if they were to take place. In particular, currently used mortality projections for retirement systems are very different from the concept of Longevity Escape Velocity:

A widely used basis for mortality projections is the Lee-Carter model (Lee and Carter, 1992). It has led to the development of numerous models (Cairns et al., 2011). In their original paper, Lee and Carter (1992) present a forecast of US life expectancy that first continues at the historical trend and then decelerates over time. Their confidence intervals are presented that are below a linear extrapolation of life expectancy. The authors write: "While many methods assume an upper limit to the human life span (...) our method allows (...) the deceleration of life expectancy (...) without any special additional assumption". At that time indeed, a sort of "longevity deceleration" was expected.

A widely known view is that life expectancy grossly increases by one quarter per year. Such a view was introduced by Oeppen and Vaupel (2002) ten years after the publication of the Lee-Carter model, in the context of maximal life expectancy across countries. They indicate that it has increased fairly linearly for more than 150 years - a "best practice line"- and has broken various predictions and limits imagined by actuaries, such as a 1928 computation of a putative ultimate human life expectancy of... 64.75 years (Dublin, 1928). Along those lines, Bongaarts (2004) questions longevity decelerations embedded in the Lee-Carter model and develops a simple mortality projection model that produces straight life expectancy increases.

Vallin and Meslé (2010) recomputed maximal life expectancy with other data and find that it is better represented by several portions of lines than by one line: the trend can change over time in particular due to various medical and social progresses. As they indicate, maximal life expectancy has increased by up to 4 months per year during several decades after the work of Louis Pasteur, the trend is now lower than "one quarter per year" and is more and more driven by improvements at later ages, in particular 
depending on how age-related frailty and age-related pathologies are addressed. Along those lines, Li et al. (2013) produce an extended version of the Lee-Carter model that allows for age patterns of mortality decline to rotate in the future towards higher ages, thereby reducing the longevity deceleration of the Lee-Carter model. Note that Ronald Lee was one of the coauthors of that paper.

One might interpret the latter as a convergence of views that a decelerating pattern of the Lee-Carter model is inadequate and that a trend of linear increases of life expectancy, which would be slower than one quarter per year for the next decades to come, makes sense. In this paper we name such a scenario the "Best Practice Trend" following the strong-worded vocabulary of Oeppen and Vaupel (2002), even if it is of course not clear at all what the best practice is, and we model it in this paper. However, views are far from uniform. There have typically been debates whether general improvements will outweigh changes in lifestyle, pollutions and climate, whether age-specific risks of chronic diseases will increase or decrease for a given age, and whether lifespan should consecutively increase or decrease and also whether a limit of human lifespan exists (Aubert et al., 2010; Cambois et al., 2010; Debonneuil et al. 2011).

Facing uncertainty, actuarial assumptions should be prudent rather than aggressive. Antolin and Mosher (2014) review the sufficiency of actuarial mortality tables that are commonly used for retirement systems, country by country. For that purpose, they compare mortality tables with projections obtained with models that extrapolate logmortality rates, such as the Lee-Carter model. They find in most of the cases that the mortality table leads to lower provisions than the model (Antolin and Mosher, 2014) thereby generating a general warning: are actuarial mortality tables sufficient? Antolin and Mosher (2014) also suggest that governments help set up a framework to financially hedge longevity risk.

Here, further than comparing commonly used mortality tables with commonly used actuarial models, we compare them with models that extrapolate life expectancy linearly. Placing then the results in the context of potentially even far different futures than generally investigated we gather facts of advances in biogerontology and elements of solutions to help retirement systems cope with strong increases in human lifespans.

\section{MORTALITY PROJECTION METHODS}

\subsection{OVERVIEW}

We here limit the modeling scope in order not to disperse into too many aspects. Complex longevity risk estimations that would consider country-specific and systemspecific risk absorption mechanisms and amounts at stake are not considered. Rather, the quantitative parts of this paper focus on life expectancies (period and generational life expectancies starting at different ages) and values of immediate annuities for people aged 65. The sole data we use here are general population data and actuarial tables, the results of which are compared without modeling complex basis risk between general and insured populations. Similarly, results for males and females are superimposed without modeling correlations between the two. For the sake of simplicity, we consider life expectancy at age 20 (and above) rather than at birth because some actuarial tables do not provide mortality rates for lower ages. Of course, this oversimplification would 
prevent one from accurately estimating longevity risk. However, it enables us to illustrate our conclusions with little complexity.

The interest of the analysis then lies in the use of models with various trends and some first order comparison with commonly used actuarial assumptions.

Briefly, for a given country and a given gender, five mortality projection models ("LeeCarter", "Bongaarts", "BestPractice”, "Fast", "Flat", "LEV”). Indicators are calibrated from the general population data. Indicators are then computed for various dates, both based on those models and based on an actuarial table for the same country and gender: [period] life expectancy at age 20 and 65, generational life expectancy at age 65 and immediate annuity value at age 65 .

\subsection{STANDARD METHODS}

Regarding data, the general population data consist in deaths and expositions taken from the Human Mortality Database for various countries (Human Mortality Database, 2015). It is split by gender, age " $\mathrm{x}$ " and calendar year " $\mathrm{t}$ ". We consider data up to calendar year 2009 only as more recent data is currently only available for a limited number of countries. The actuarial mortality tables are those commonly used in insurance according to a recent report from the OECD about the insufficiency of current actuarial assumptions (Antolin and Mosher, 2014).

Regarding indicators, annual mortality rates $q_{x, t}$ are computed from central mortality rates $m_{x, t}$ using

$$
q_{x, t}=1-e^{-m_{x, t}}
$$

The remaining [period] life expectancy at age $\mathrm{x}$ is computed using $e_{x, t}=0.5+$ $\sum_{y=x}^{170} \prod_{z=x}^{y}\left(1-q_{z, t}\right)$

The expected lifespan of people aged 65 at year $\mathrm{t}$ is computed using

$$
e_{g 65}^{t}=65.5+\sum_{x=65}^{\infty} \prod_{y=65}^{x}\left(1-q_{y, t+(y-65)}\right)
$$

In practice we replace $\infty$ by 170 (except for the LEV model where we use 10000). Immediate annuities at age 65 are calculated similarly, with an interest rate of $2 \%$ :

$$
\ddot{a}_{65}^{t}=65.5+\sum_{x=65}^{\infty} \frac{\prod_{y=65}^{x}\left(1-q_{y, t+(y-65)}\right)}{1.02^{x-64}}
$$

We will compute them with standard mortality tables $\left(\ddot{a}_{65 \text { (table })}^{t}\right)$ and various models $\left(\ddot{a}_{65(\text { model })}^{t}\right)$.

Regarding the Lee-Carter model, parameters are calibrated for ages 0 to 89 with the LifeMetrics "fitmodels.r" functions (see Cairns et al., 2007), which is an implementation of an adjustment of the original Lee-Carter model (see Brouhns et al., 2002). The longevity trend is obtained by extrapolating kappa with a simple linear regression (slope defined by least square linear regression, and applied to the last known kappa; for further refinements, it could be possible to apply trends to an average of the last 3 years for 
example): we obtain central mortality rates $m_{x, t}$ for ages 0 to 89 and at any future date. For any given date $t$ we then extrapolate $m_{x, t}$ from ages 60-89 to ages 90-170 using a logistic regression: logit $m_{x, t}=a_{t} x+b_{t}$. This is simple and sufficient for the gross indicators that we use in this paper such as life expectancies at age 20 and 65. To smooth mortality rates along age and time one may extrapolate mortality rates at high ages in a coherent manner across consecutive years following Planchet (2006).

Regarding the "Bongaarts" model, sometimes called "shifting logistic", we carry out a standard logistic regression on deaths and expositions with respect to age and time: logit $m_{x, t}=A+B x+C t$. Similarly, to the application of the trend to the last kappa for the Lee-Carter model, we recalibrate the mortality level $(A)$ on the data of the last year logit $m_{x, t}=A^{\prime}+B x+C t$ and we apply trends to the last year. Bongaarts (2004) demonstrates that the model naturally produces linear life expectancy at birth (or low ages for which mortality rates are small).

\subsection{BEST PRACTICE TREND MODEL}

To define the strong-worded "Best Practice Trend" model, we first compute the "best practice" life expectancy at different ages based on all countries available in the Human Mortality Database since 1900. For retrospective projections that are based on data up to the year 1990, we use a second order polynomial fit between 1900 to 1989 of the best practice life expectancy at age $20\left(B P_{20, t}=\alpha_{20} t^{2}+\beta_{20} t+\gamma_{20}\right)$ and $65\left(B P_{65, t}=\alpha_{65} t^{2}+\right.$ $\left.\beta_{65} t+\gamma_{65}\right)$ to directly extrapolate "Best Practice Trend" life expectancies of any country between 1990 and 2009 at age 20 or 65 at the same polynomial pace: $e_{x, t}=e_{x, t 0}+$ $\left(B P T_{x, t}-B P T_{x, t 0}\right)$. Results are shown in Figure 1.

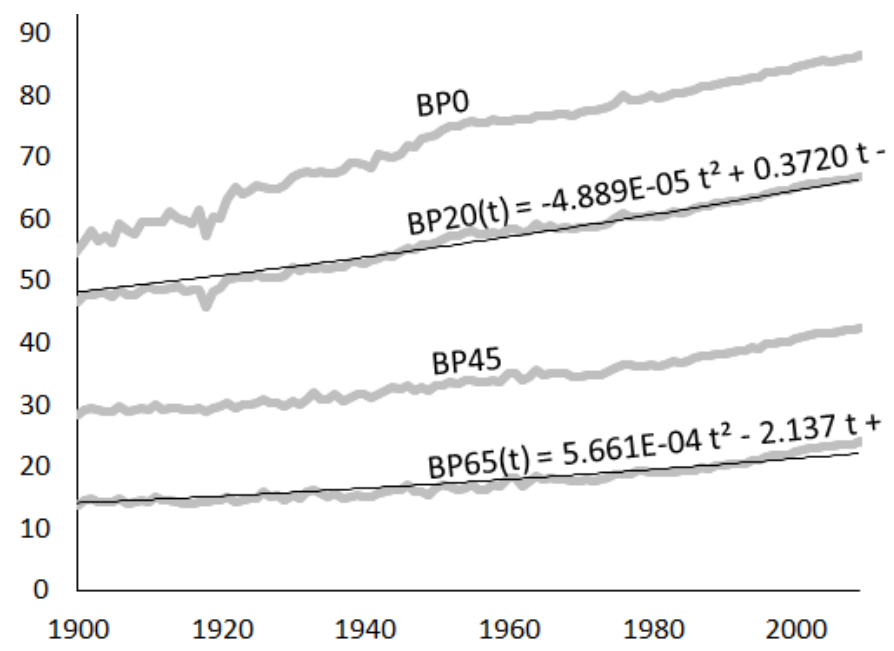

Figure 1. Best practice life expectancy at ages $0,20,45,65$ (in years) across all countries and genders available on the Human Mortality Database, between 1900 and 2009. Second order polynomial fits between 1900 and 1989 for ages 20 and 65 .

For future predictions that are based on data up to the year 2009 for each country and gender, we define the "Best Practice Trend" model as a Bongaarts model that is constrained to have a desired trend in terms of life expectancy: $\operatorname{logit} m_{x, t}=A+B(x+$ $s t)$. A and B are calibrated by maximum likelihood, as a standard logistic regression. We choose the trend $s=20 \%$, since the polynomial fit between 1900 and 2009 of the best practice life expectancy at age 20 yields roughly linear increases of $20 \%$ per year (from $19 \%$ to $21 \%$ between 2010 and 2100; less than "one quarter per year" which would be $s=25 \%$ ); 
keeping in mind that mortality rates produced by the model from birth to age 20 have little impact on the computed life expectancy (Bongaarts, 2004). As a verification of the assumption, for every country and gender and every year from 2000 to 2100 we have measured that the year slope of the resulting $e_{20, t}$ is between 0.199 and 0.20 per year.

Of note, we could certainly have used a unique model for both retrospective and future analyses logit $m_{x, t}=A+B\left(x+\alpha_{20} t^{2}+\beta_{20} t\right)$, but to avoid complex interpretations of results we did not want the model used for future analyses to produce life expectancy accelerations.

\subsection{EXTREME PROJECTIONS}

During seven decades following the work of Louis Pasteur, the best practice life expectancy has accelerated by 4 months per year (Vallin and Meslé, 2010). Based on that historical pace we define a "Fast" model that uses the Best Practice Trend model until 2025 and that then increases life expectancy by 4 months every year: $\operatorname{logit} m_{x, t}=A+$ $B(x+0.22025+(t-2025) / 3)$. Similarly, in order to consider scenarios of nonincreasing life expectancies, we define a "Flat" model where the Best Practice Trend model is used until 2025 and then mortality rates do not evolve anymore. We also introduce a "Decreasing" model where life expectancy decreases at the pace of 4 months per year starting at 2025: $\operatorname{logit} m_{x, t}=A+B(x+0.22025-(t-2025) / 3)$. The choice of 2025 is arbitrary but the reason of starting the change of trends later than 2015 is that we are not aware of signs that would indicate that such a change of trend should happen now. As an attempt to model the Longevity Escape Velocity (LEV) announced by de Grey (2015), we define a "LEV" model that is first a Best Practice Trend model and then performs adaptations: for ages 85 and above starting at 2040, 84 and above starting at 2041,83 and above starting at 2042, and so on, mortality rates are defined by annual mortality improvements of $5 \%: q_{x, t+1}=q_{x, t}(1-5 \%)$. Starting with the Best Practice Trend model for France for example (men and women combined), that model respectively gives a $61 \%$ and $85 \%$ probability for people currently aged 40 and 20 to reach Longevity Escape Velocity: close to the announced $60 \%$ and $80 \%$. The underlying real life scenario - whether realistic or not - would be that a set of medical or pharmaceutical procedures would first reach a mass usage at ages 85 and above in 2040 and would then gradually reach younger ages. Given improved research guidance after first successful results, as well as a consequent increased awareness and attention to improve health, such procedures would on average decrease age-specific mortality rates by $5 \%$ per year. Sustained mortality improvements of $5 \%$ at high ages may at first not seem extreme but they actually lead to life expectancies of more than 1000 years for people currently aged 40 ! Sustained mortality improvements of $4 \%$ would also lead to Longevity Escape Velocity but to approximately match the announced probabilities they should start within the next few years.

\section{COMMONLY USED MORTALITY TABLES PRODUCE DECELERATING LIFE EXPECTANCIES}

\subsection{DECELERATING COMMON ACTUARIAL TABLES, BY COUNTRY}

In order to compare common actuarial mortality tables with various projection models, for every country available at the Human Mortality Database for which a commonly used annuity table is studied in the OECD report (Antolin and Mosher, 2014) we computed the 
life expectancy at age 20 up to year 2100: i) historically, ii) with the actuarial tables and iii) various models: Lee-Carter (with two calibration periods), Bongaarts, Best Practice Trend ("+20\%/year"). The results are shown in Figure 2 and Figure 3 


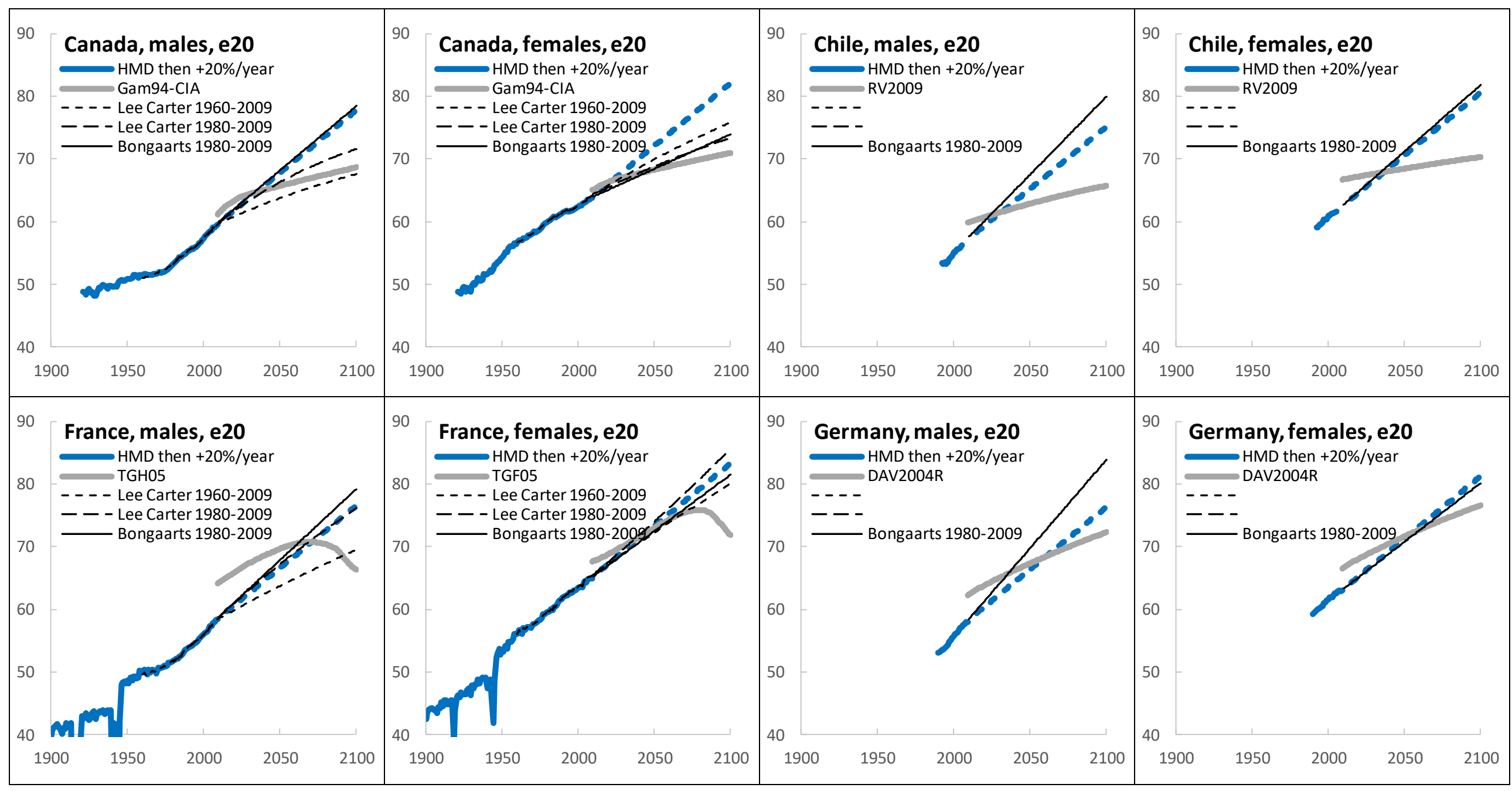

Figure 2. Comparison of past and projected life expectancy at age $\mathbf{2 0}$ for males and females according to commonly used actuarial tables and general population models for Canada (actuarial table GAM1994-Scale CIA), Chile (RV2009), Germany (DAV2004R). Historical life expectancy is shown in thick continuous blue lines and extended with a linear slope of $20 \%$ (Best Practice Trend method) in thick dashed blue lines. In contrast, actuarial tables are in thick continuous grey lines and are observed to have a much lower trend. The thin black lines correspond to models that aim at extrapolating the historical trend of the country: the Lee- 


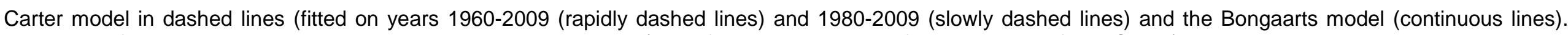
When one of those could not be correctly computed, it is not shown (lack of convergence in the fitting program of Lee-Carter).

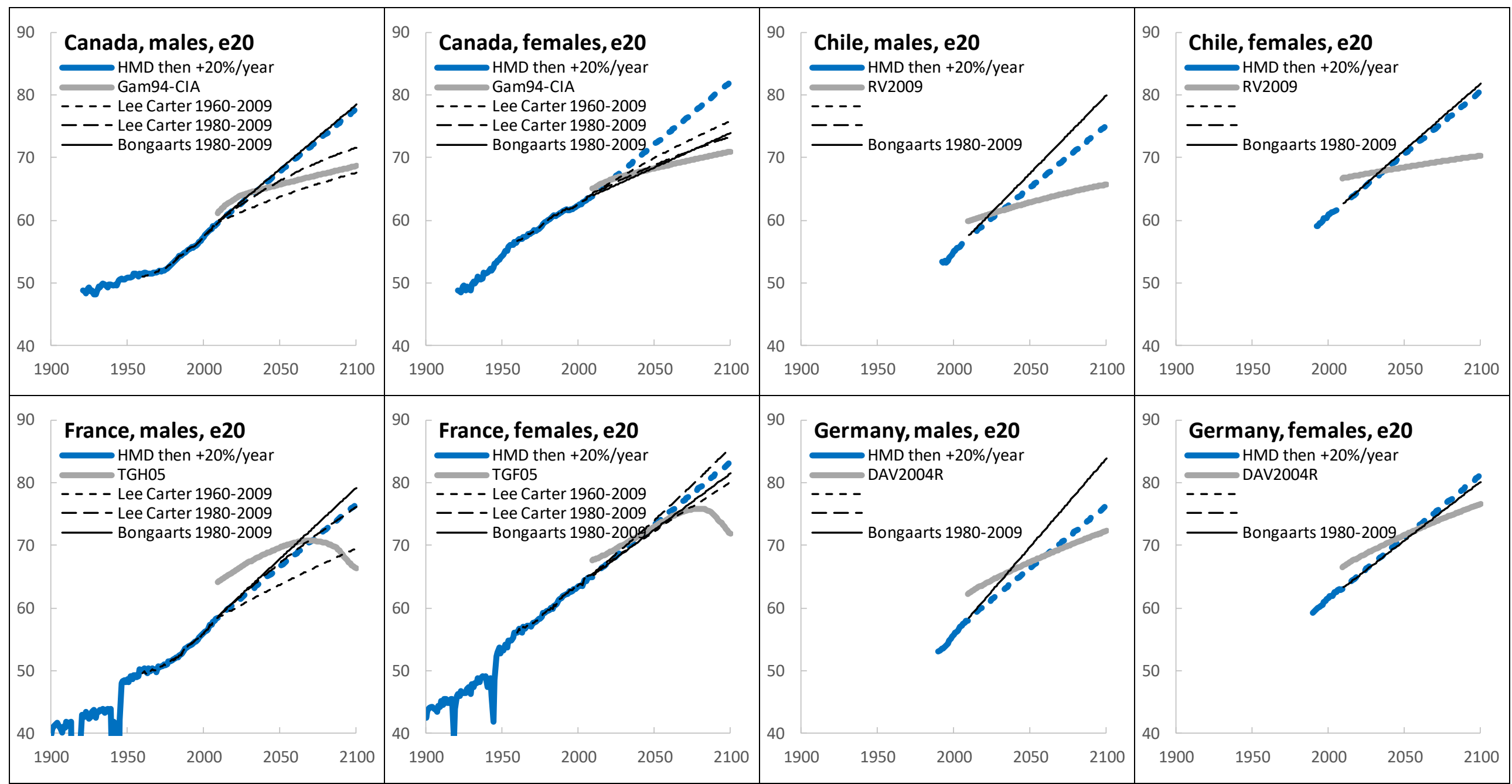

Figure 2. Comparison of past and projected life expectancy at age $\mathbf{2 0}$ for males and females according to commonly used actuarial tables and general population models for Canada (actuarial table GAM1994-Scale CIA), Chile (RV2009), Germany (DAV2004R). Historical life expectancy is shown in thick continuous blue lines and extended with a linear slope of $20 \%$ (Best Practice Trend method) in thick dashed blue lines. In contrast, actuarial tables are in thick continuous grey 


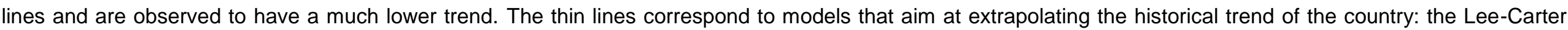

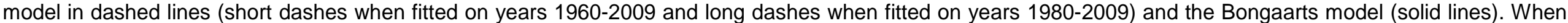
one of those could not be correctly computed, it is not shown (lack of convergence in the fitting program of Lee-Carter).

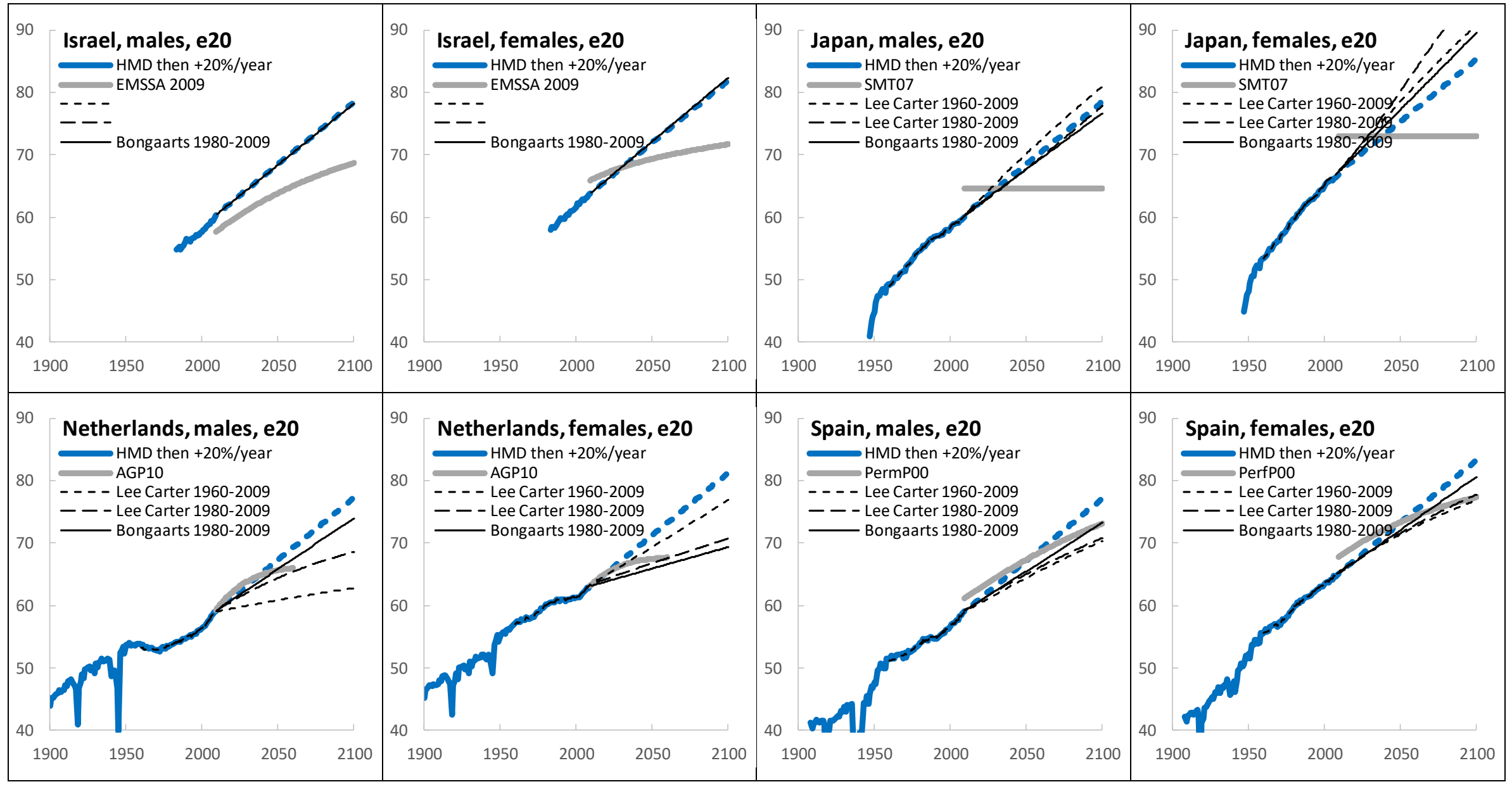




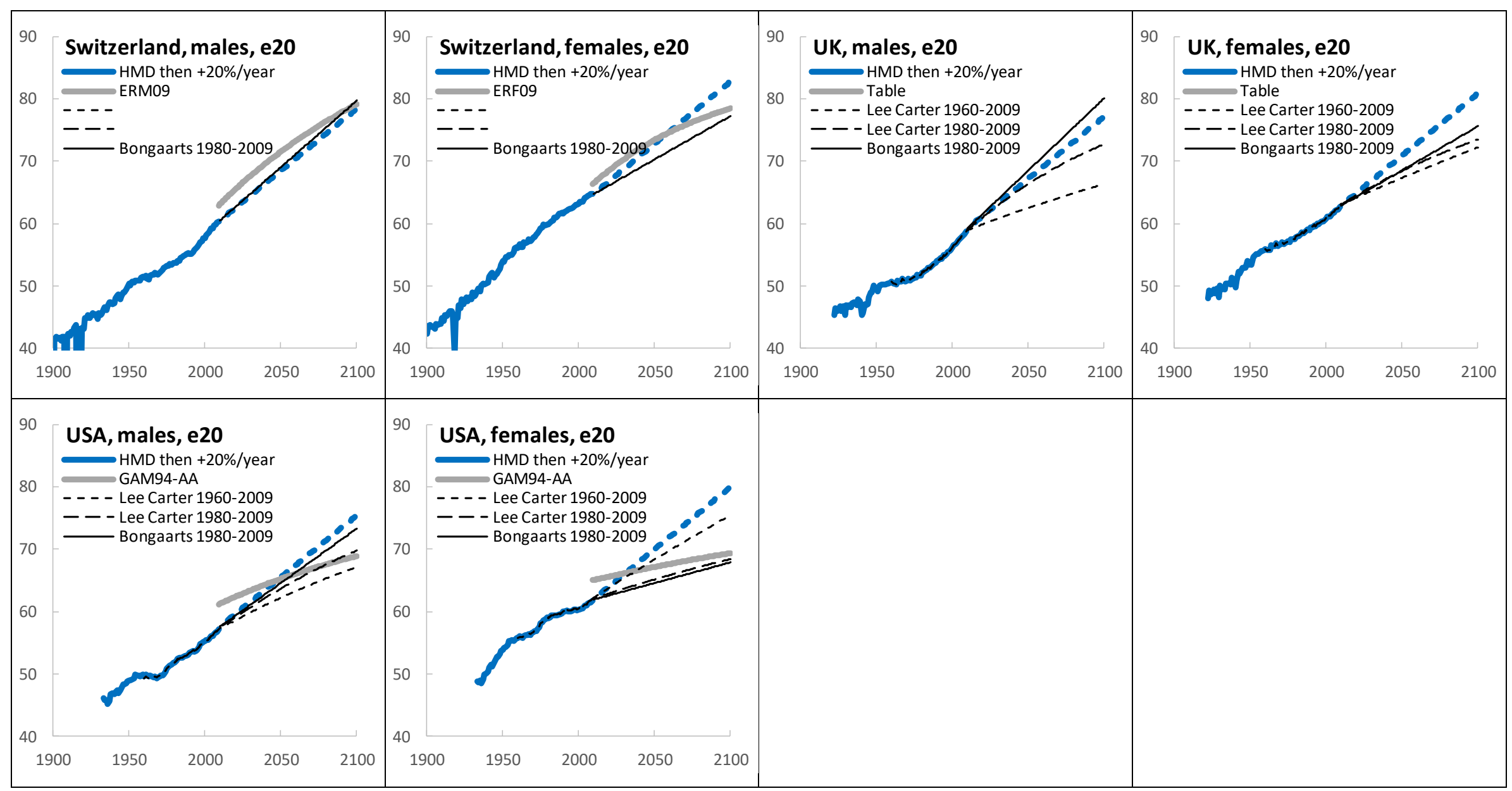

Figure 3 (continuation of figure 2). Comparison of past and projected life expectancy at age 20 for males and females according to commonly used actuarial tables and general population models for Israel (EMSSA 2009), France(TG2005), Japan (SMT2007), Netherlands (AGP2010), Spain (PERMC), Switzerland (ERM2009), UK, USA (GAM1994-Scale AA). 
Let us for example consider the case of Canada (first two graphs of Figure 2). For males, the Best Practice Trend and the Bongaarts models for linear life expectancy extrapolation are aligned. The Lee-Carter models start similarly but very rapidly produce lower life expectancies: they produce longevity deceleration (to a stronger degree when not focusing on recent data). Compared to those models, the common actuarial projection table (Gam94-CIA) starts with higher life expectancies - it makes sense as insured persons tend to live longer than the general population - but rapidly produces lower life expectancies than modeled for the general population with linear extrapolation models (Best Practice Trend, Bongaarts) and even here lower than the Lee-Carter model calibrated with recent data. It could be interpreted as a warning for the commonly used actuarial table: are provisions for retirement sufficient? It could also be seen as individuals with lower life expectancy catching up with favored individuals. To avoid this crossing, two-population models have been proposed (see Salhi and Loisel 2012 and Cairns et al. 2015). If such a population mix would lead to a life expectancy deceleration, it would be unexpected however to lead to low remaining lifespans of retired persons as seen further below.

For females, results are visually more complex as the Bongaarts projection is much lower than the Best Practice Trend. This is not surprising as life expectancy has particularly low increases during the calibration period of the Bongaarts model. The Lee-Carter models seem to start similarly to the Best Practice Trend but they rapidly produce lower life expectancies, still greater though than the (again here low) Bongaarts predictions. As for males, compared to those models, the common actuarial projection table starts with higher life expectancies and rapidly down crosses other curves. Again, it could be interpreted as a warning for the commonly used actuarial table: are provisions for retirement sufficient?

Overall, Figure 2 and Figure 3 show a variety of cases. The following common features appear:

i) Except for the Japanese tables that do not attempt to project trends, all commonly used actuarial tables studied here project decelerating life expectancies - with longevity trends that are globally smaller than in the past. This explains the title of this paper: "Do Actuaries believe in longevity deceleration?". In most cases, within a few decades, the life expectancy of the actuarial table becomes lower than here modeled for the general population, although it would be expected that insured populations keep higher life expectancies than general populations: are provisions for retirement sufficient?

Given the potential amounts at stake, we highlight below some mathematical explanations of why the commonly used assumptions behave that way. We further investigate the likely insufficiency of the tables, and we discuss the gravity of the situation in the discussion section. In the documents describing the methodologies pursued to obtain those tables, we have not read that there was a voluntary deceleration.

ii) While using the actuarial tables, we have noticed that for most of the tables studied here (all except for the UK, Japanese and French tables), the construction of the actuarial table is similar to a Lee-Carter model: mortality rates at a given age decrease exponentially with time at an age-specific rate (similar rather than identical because LeeCarter produces an exponential decrease of $t \rightarrow m_{x, t}$ rather than $\left.t \rightarrow q_{x, t}\right)$. For some tables (such as DAV 2004R), there is a short, initially different, transition period, but it then becomes again is similar to a Lee-Carter model too.

This might be one of the explanations of the deceleration as for all those countries the Lee-Carter models shows life expectancy deceleration. Below, we investigate the 
mechanism of such deceleration produced by the Lee-Carter model and such tables. We also explain why the Lee-Carter models here produced longevity acceleration in France and Japan.

iii) The French and Japanese actuarial tables are not built similarly to Lee-Carter models. Japanese tables are mortality rates that do not evolve over time: it is transparently hoped that the initial prudence of these mortality rates is sufficient to compensate the absence of trend in the table, until the next table. The French table has a complex construction: the decrease of life expectancy at age 20 that is produced after 2070 should not be a warning in itself as it comes from a specific closure that is applied for generations for which no data is available (Planchet 2006) rather than a limitation for current generations. Therefore, for these two countries more than for others, sufficiency or insufficiency should rather be analyzed with generational life expectancies, which is done below.

iv) In most cases the Bongaarts predictions are close the Best Practice Trend. In the other cases, the trend was particular during the fitting period used for the Bongaarts model. There are actually many reasons for the latter to happen. We have already seen that for Canadian females life expectancy increases varied much over time. Fitting over a longer period here leads to much closer results (data not shown), but for some countries like France fitting over long periods leads to strange results due to the impact of wars. For Chile and Germany, due to the limited availability of data, the Bongaarts model was fitted on short periods of time (1992-2009 and 1990-2009 respectively). On such small periods the measure of the trend is of course delicate. In both cases, the Best Practice Trend model cannot be discarded.

Moreover, the case of Japan highlights some 'neutral' aspect of the best practice trend approach: many developing countries have fast life expectancy increases as they 'bridge the gap' towards longest lived countries (World Health Organization, 2015). Countries of ex-USSR have in the contrary 'created a gap'. For those countries with particular current trends, it is not obvious whether current trends are likely to continue or even 'reverse' (creating or bridging the gap back). Using the trend of the best practice is then a way to choose a neutral view, in the absence of country-specific contextual knowledge. Of course, socio-economic forecasts are of first-order relevance for longevity prediction in those countries.

Therefore, for the sake of simplicity, in what follows we shall use the best practice trend as a reference to estimate possible insufficiency of tables. We shall keep in mind however that specific knowledge about each country (i.e., whether their specific ongoing trend is temporary or likely to continue) would likely adjust views, including for example population dynamics such as birth patterns (Boumezoued, El Karoui and Loisel, 2015).

\subsection{WHY DO COMMON ACTUARIAL TABLES AND MODELS PRODUCE LIFE EXPECTANCY DECELERATION, MATHEMATICALLY SPEAKING?}

Here we try to understand the longevity deceleration embedded in commonly used actuarial tables. In fact, most tables studied above behave similarly to Lee-Carter in that by construction they have age-specific mortality improvements $i_{x, t}=\left(q_{x, t+1}-q_{x, t}\right) / q_{x, t}$ that differ by age but are constant with time. This is sufficient to create longevity deceleration - as schematized in Figure 4 - if age-specific mortality improvement rates diminish after a given age. For the sake of simplicity we mention the Lee-Carter model but 
some widely used similar models like the Cairns Blake Dowd models (Cairns et al., 2011) also create mortality improvements that vary by age (roughly linearly, by construction) and are roughly constant with time; they therefore have the same behavior.

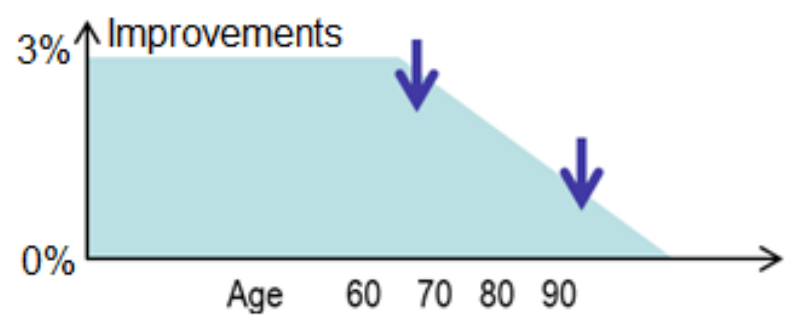

Figure 4: Schematized explanation of the longevity deceleration. Mortality improvements are here schematized by age. What matters is that they decrease past a certain age (here past 60-70 years of age). The arrow above age 60-70 typically indicates the ages where mortality improvements currently drive life expectancy the most. As time passes, mortality rates become lower and people live longer. Most important ages to remain alive or not decay to the right, as symbolized by the arrow above age 90. At that age, mortality improvements are very low which means that the drivers of longevity are then very low: a 'longevity deceleration' has been modeled. Ultimately, if important ages to remain alive decay to ages with negligible mortality improvements then there is no more driver of longevity and life expectancy reaches a ceiling.

To be more precise than in Figure 4, we can check that some ages are more important than others for life expectancy, in terms of mortality improvements. For consistency let us consider life expectancy at age 20.

Let us split the probability to live from age 20 to age $y(>x)$ into three probabilities: the probability to live until age $x$, the conditional probability to then remain alive until age $x+1$ and the conditional probability to then remain alive until age $y$ :

$$
S_{20 \rightarrow y}=\prod_{z=20}^{z=y-1}\left(1-q_{z}\right)=S_{20 \rightarrow x}\left(1-q_{x}\right) S_{x+1 \rightarrow y}
$$

This allows decomposing the life expectancy in a way that highlights its dependence on $q_{x}$ :

$$
e_{20}=0.5+\sum_{y=20}^{170} S_{20 \rightarrow y}=0.5+\sum_{y=20}^{x} S_{20 \rightarrow y}+\sum_{y=x+1}^{170} S_{20 \rightarrow x}\left(1-q_{x}\right) S_{x+1 \rightarrow y}
$$

The first two terms do not involve $q_{x}$. Regarding the last term, $\left(1-q_{x}\right)$ can be factored out. So we get the following derivative:

$$
\frac{d e_{20}}{d q_{x}}=-\frac{d e_{20}}{d\left(1-q_{x}\right)}=-S_{20 \rightarrow x} \sum_{y=x+1}^{170} S_{x+1 \rightarrow y}=-S_{20 \rightarrow x}\left(e_{x+1}+0,5\right)
$$

Since we want to see the changes of life expectancy driven by relative variations of $q_{x}$ (mortality improvements) rather than absolute variations, we multiply by $q_{x}$ and we get

$$
e_{20, t+1}-e_{20, t}=\sum_{x=20}^{170} w_{x, t} i_{x, t}
$$

where 


$$
w_{x, t}=q_{x, t} S_{20 \rightarrow x}\left(e_{x+1, t}+0,5\right)
$$

The formula provides weights by which improvement factors must be multiplied to compute increases in life expectancy. Figure 5 tests it for Japanese females: it is an interesting case because depending on the period on which the Lee-Carter model is fitted it can produce accelerating or strongly decelerating longevity - visualizing the shape of mortality improvements past age 60 provides the explanation. Also, it shows that very strange extrapolations of kappa would be needed for the naturally decelerating LeeCarter model not to produce decelerating life expectancy. This would not be achieved with usual ARIMA extrapolation of kappa. In Figure 6, visualizing the mortality improvements of the various actuarial tables studied above explains the deceleration as well.
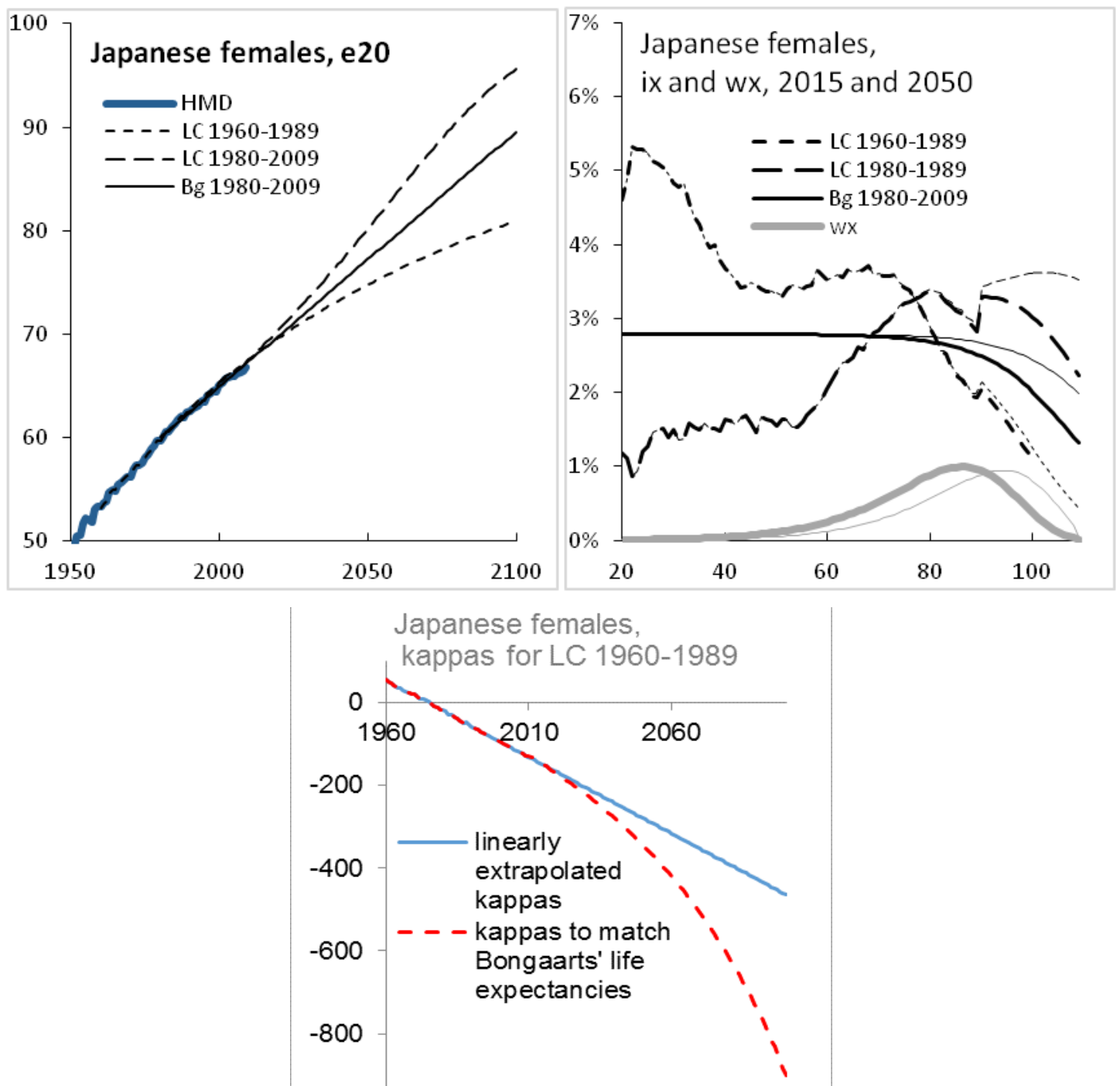

Figure 5. Deciphering accelerating and decelerating longevity mechanisms. The graph on the top left shows historical life expectancy at age 20 and its projection with 3 models. The case of Japanese females is taken because out of the 3 projection models, one produces an acceleration (Lee-Carter model fitted on years 1980-2009; long dashes), one extrapolates life expectancy linearly (Bongaarts model, solid line in the middle) and one produces a deceleration (Lee-Carter model fitted on years 1960-1989; short dashes). The graph on the bottom highlights that the difference between the two latter projections is important by indicating which kappa extrapolation of the Lee-Carter 19601989 model would be needed to move, in the top left graph, the decelerating short dashes to the nondecelerating solid line (it was obtained by calibrating kappa in order to reach the desired life expectancy): such kappa are far from a linear or even simple ARIMA extrapolation of past kappa. The 
right-hand side panel attempts to explain why the Lee-Carter model sometimes decelerates or accelerates life expectancy. It shows the corresponding mortality improvements with the same lines style as the top left graph and the weights in a thick gray line (thinner lines for the year 2050 than the year 2015). In 2015, what matters is improvements for ages 60-100 with a focus on ages $80-90$ (thick gray curve). It explains that life expectancy increases faster with the 1980-2009 Lee-Carter calibration than the 1960-1989 Lee-Carter calibration. In 2050, what matters is improvements about 7 years later. The decreasing improvements by age of the 1960-1989 model explain the deceleration; the globally increasing then globally decreasing mortality improvements by age of the 1980-2009 model explain the acceleration then deceleration. Similarly, for each country the shape of improvements by age after age 60 explain the more or less pronounced deceleration of the Lee-Carter model (data not shown). The Bongaarts model has decreasing mortality improvements after a certain age but no deceleration is produced as they decay to the right with time.
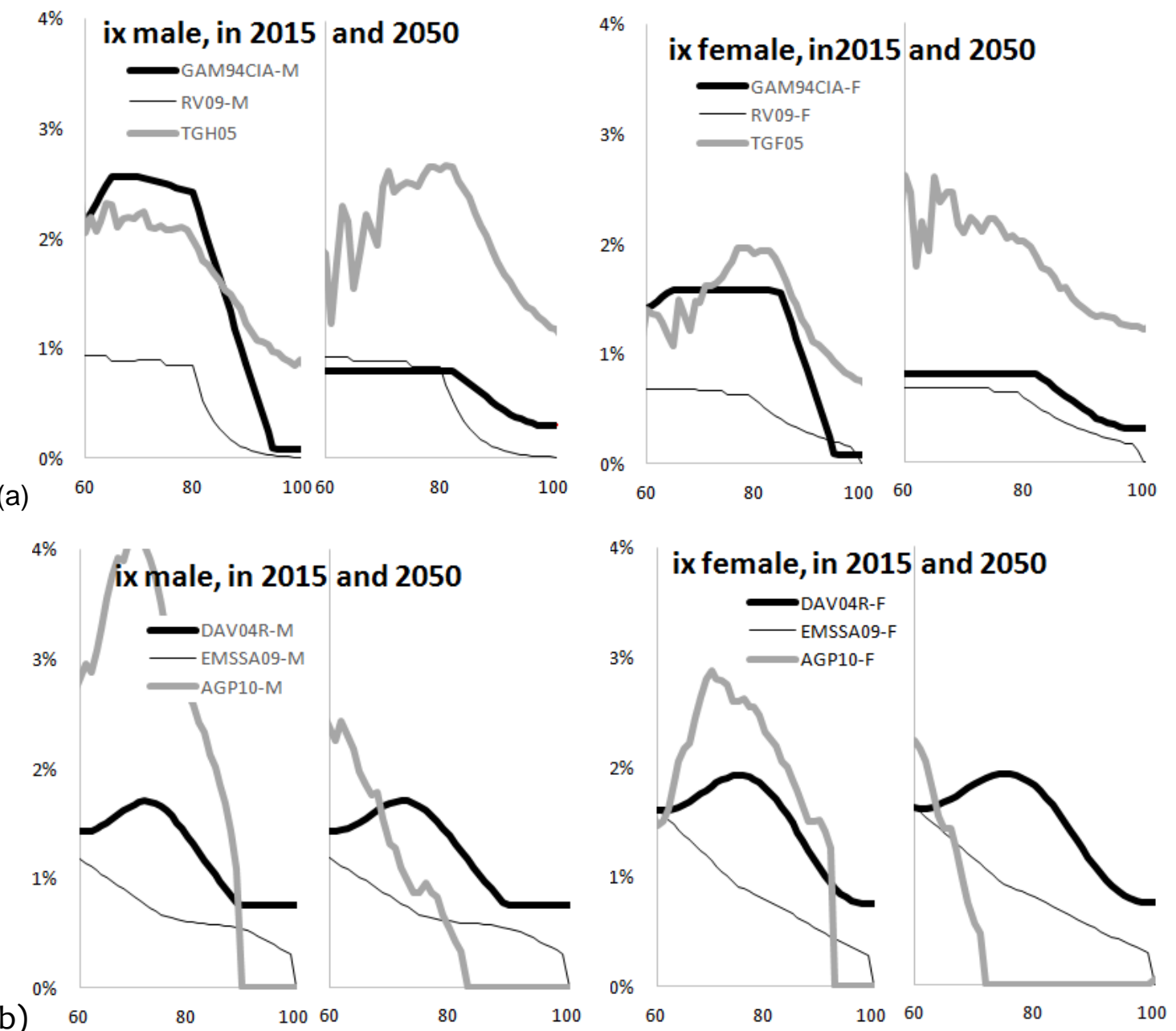

(b)
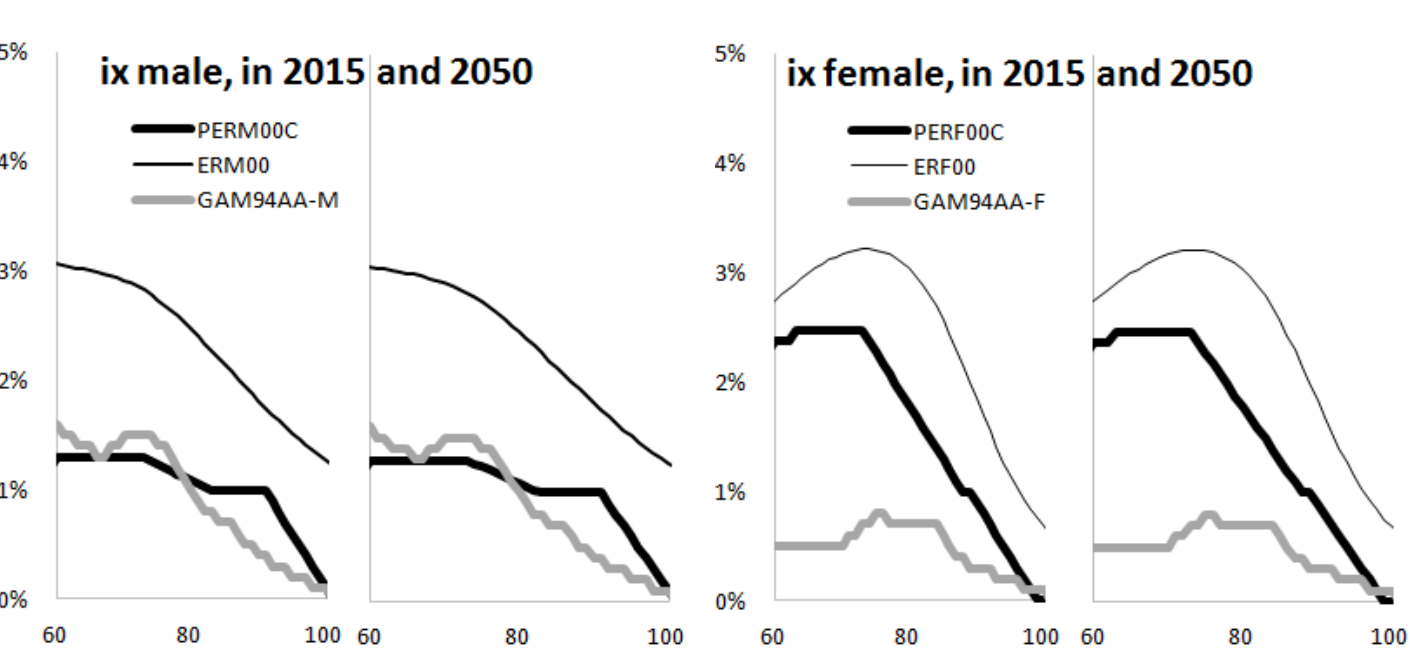
Figure 6. Mortality improvements by age for the various tables studied, in 2015 and 2050 . SMT07 is not represented since it has no improvement. The $x$-axis is only shown from age 60 to 100 in order to focus on mortality improvements that materially impact lifespans. The 9 tables are put in 3 groups of 3 by alphabetical order of the country: (a), (b), (c). It is immediate to detect the tables that behave like Lee-Carter and those that do not, depending on whether the same curves appear in 2015 and 2050 (left and right parts of each panel). All curves plunge down after age 80, which, according to the explanations given above leads to longevity decelerations. Some plunge to zero, which leads to life expectancy ceilings over time. Between age 60 and 80 , some curves increase, which counterbalances the deceleration for some time. Visually, those graphs explain the shapes observed in Figure 6 for actuarial tables up (except for the French TGHF05 after 2080: a specific closure leads to strong decelerations).

We hope that such visualization will help the reader rapidly realize that some model have decelerating behaviors. Of course, if the model contains no mortality improvement after a certain age then in the long term life expectancy will even tend not to increase anymore. From a social and biomedical point of view, a "longevity-optimistic" person may think that there would rather be people to investigate and find solutions with respect to the most important reasons to get ill and die.

As this section explains the longevity deceleration embedded in actuarial tables, one should also note that an additional late longevity deceleration factor comes from the closure of tables. To make the point particularly clear, while it is today rare to reach the age of 100, it could become quite common in a few decades. Tables that give a $100 \%$ mortality rate at age 100 will produce an additional longevity deceleration compared to a table that instead does so at age 130 (or 170!).

\subsection{A RETROSPECTIVE ANALYSIS ARGUES FOR NON-DECELERATING, NON-EXTRAPOLATIVE TRENDS}

So far, the paper has been looking at future predictions. One can get additional insight from a retrospective analysis. We here use the Lee-Carter, Bongaarts and Best Practice Trend models to compute remaining life expectancies at age 20 and 65 at year 2009 based on data up to 1989 . We do so for the 24 countries for which this is possible for males and females (i.e. data is available at those dates and the Lee-Carter fitting method converges) out of the 37 countries of the Human Mortality Database. The results are shown in Figure 7. 
E. Debonneuil, S. Loisel, F. Planchet

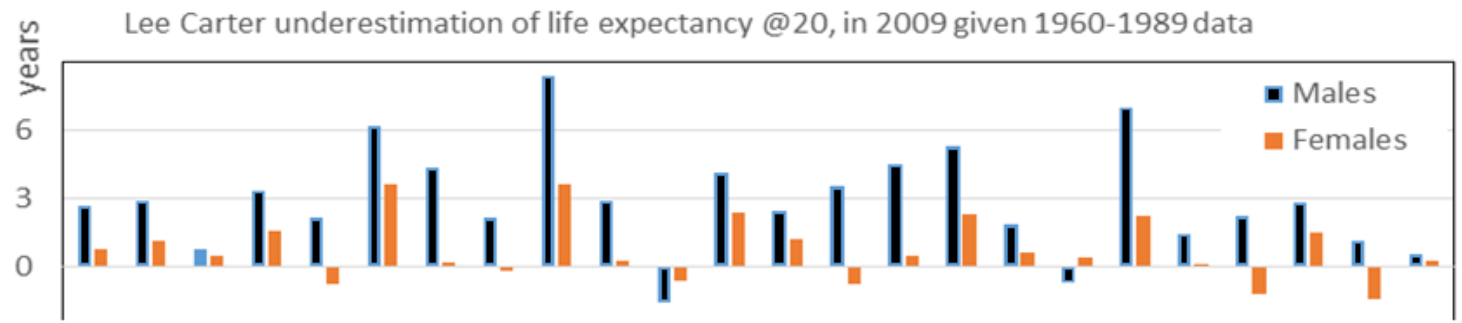

Lee Carter underestimation of life expectancy @65, in 2009 given 1960-1989 data
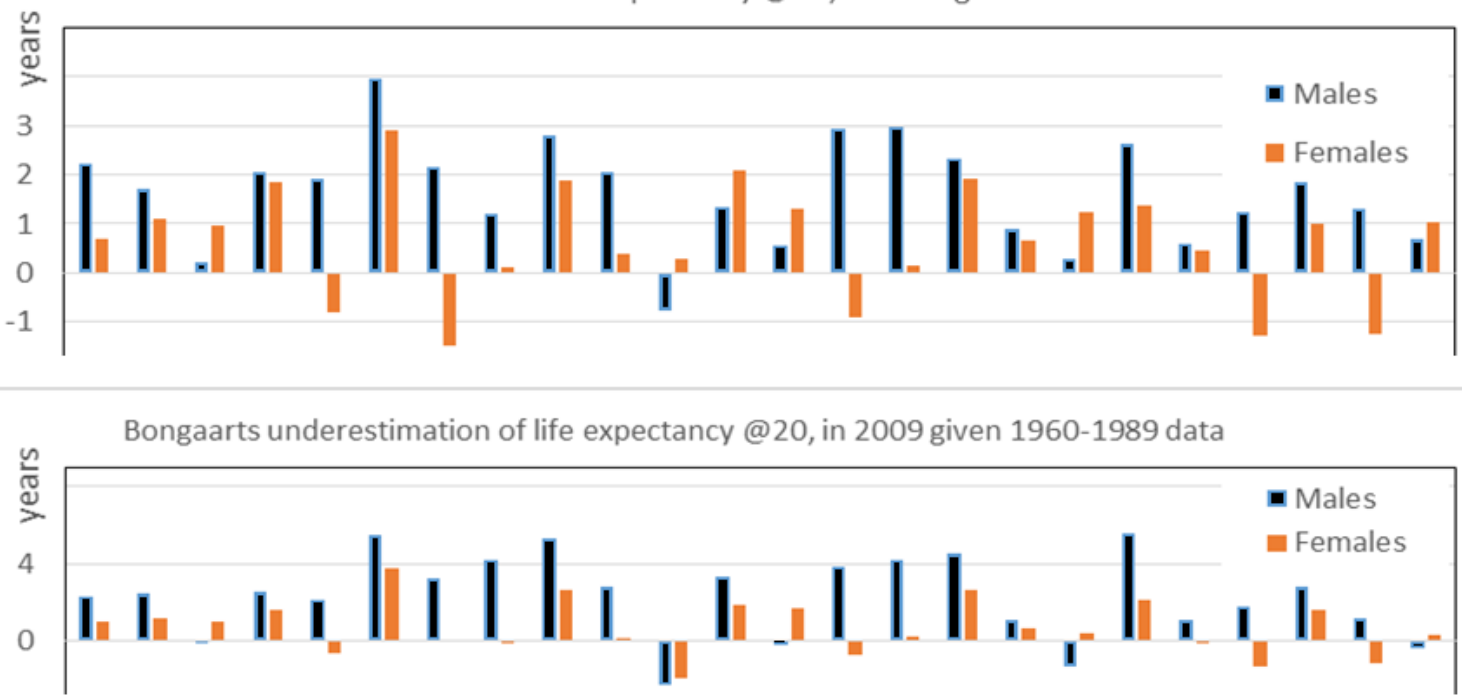

Bongaarts underestimation of life expectancy @65, in 2009 given 1960-1989 data

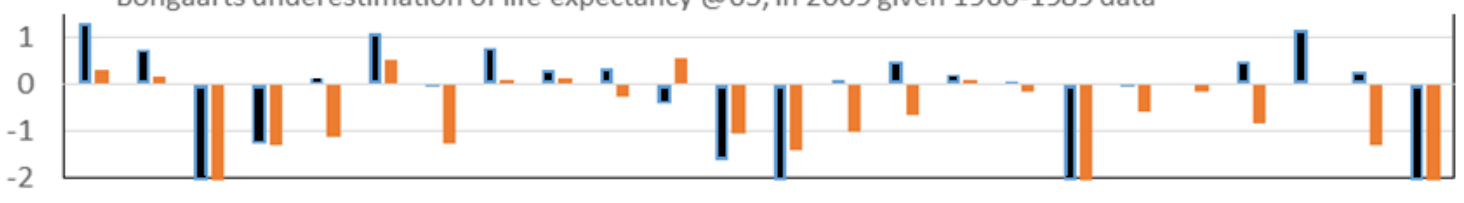

Bongaarts underestimation of life expectancy @20, in 2009 given 1960-1989 data

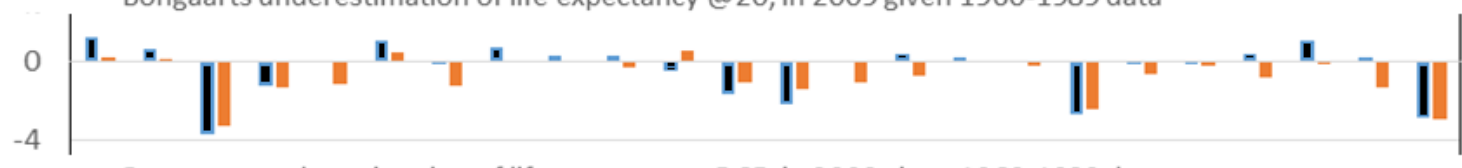

Bongaarts underestimation of life expectancy @65, in 2009 given 1960-1989 data

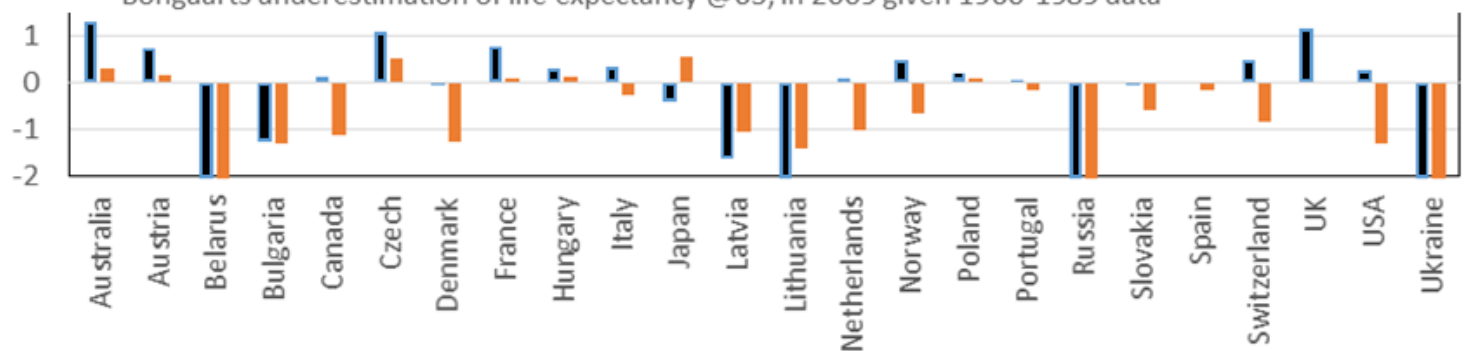

Figure 7. For 24 countries, difference between actual and predicted life expectancy in 2009 based on general population data up to 1989. It is computed for life expectancies at age 20 and 65 (alternating graphs), for males and females, and with the following prediction models: the Lee-Carter model (first two graphs), the Bongaarts model (two next graphs) and the Best Practice Trend (last two graphs). The fitting period for the Lee-Carter and Bongaarts models is 1960-1989.

The results of Figure 7 indicate that:

i) The Lee-Carter model globally underestimated longevity: predictions underestimated life expectancy in $86 \%$ of the cases ( 83 among 96) and the few prudent cases were not prudent by much compared to the lack of prudence otherwise. 


\section{DO ACTUARIES BELIEVE IN LONGEVITY DECELERATION?}

ii) However, the longevity deceleration of the Lee-Carter model is not the major culprit here. Indeed, the Bongaarts model, that produces straight life expectancy increases, produced similar patterns (Figure 7).

iii) The Best Practice Trend model produced much better results, but also much better understanding of the results, that holds in two aspects: it slightly underestimated the longevity of most developed countries and overestimated the longevity trend of ex-USSR countries that was particularly not important during that period.

Results seem in favor of the Best Practice Trend when one does not have a more precise view that would come from country specificities or specific expected advances in longevity improvements. Of course, even if longevity ends up decelerating after some time, such improvements, if prolonged long enough, may threaten pension schemes.

\subsection{CONSEQUENT LONGEVITY RISK}

The above [period] life expectancy at age 20 is an indicator that takes some snapshot of mortality rates at a given year. But the 'longevity risk' faced by insurers and pension funds largely depends on mortality rates for a generation rather than of a given year, especially when individuals enter retirement, close to age 65 . The amounts they shall receive for the rest of their life indeed depend on their accumulated capital and on how long the actuarial tables expect them to live on average.

As a second indicator, we therefore compute expected generational lifespans for people aged 65. In Table 1 we do so for insured persons using actuarial tables and for general populations using the best practice model. We compare the two and we gray results that suggest that a table would be insufficient if the best practice trend scenario occurred. If one believes in this scenario, then the results seem worrying as i) none of the tables studied has a comfortable difference today of lifespan between insured and general populations ii) the issue is expected to get worse as most tables project surprisingly low improvements (last column) and indeed iii) in 2020 two thirds of the tables even project lower lifespans for insured than for the general population. Given the weight of retirement in economics, the gray results therefore suggest probable large increases of debt to come, year after year as people enter retirement, if life expectancy continued to increase by nearly one quarter per year and if nothing were done to compensate that longevity risk. 


\begin{tabular}{|c|c|c|c|c|c|c|c|c|c|c|c|}
\hline $\begin{array}{l}\text { Country \& } \\
\text { table tested }\end{array}$ & Gender & $\begin{array}{l}\text { Best F } \\
e_{g 65}^{2099},\end{array}$ & $\begin{array}{r}\text { Dract } \\
e_{g 65}^{2015} \\
\end{array}$ & $\begin{array}{l}\text { Trend } \\
20 \\
5\end{array}$ & $\begin{array}{r}\text { Actu } \\
e_{g 6}^{200}\end{array}$ & $\begin{array}{l}\text { al ta } \\
\text { on }\end{array}$ & & $\begin{array}{l}\text { Diffe } \\
\Delta e_{g 6}^{20} \\
\end{array}$ & & & $\begin{array}{l}\text { \%Trend } \\
2009 \rightarrow 2020\end{array}$ \\
\hline Canada & Male & 85.7 & 86.8 & 87.7 & 85.8 & 86.5 & 86.9 & 0.1 & -0.1 & -0.8 & $55 \%$ \\
\hline GAM94-CIA & Female & 89.2 & 90.4 & 91.4 & 88.2 & 88.7 & 89.0 & -1.0 & -1.7 & -2.4 & $36 \%$ \\
\hline Chile & Male & 84.4 & 85.3 & 86.2 & 84.3 & 84.6 & 84.8 & -0.1 & -0.7 & -1.4 & $28 \%$ \\
\hline RV09 & Female & 87.9 & 89.1 & 90.1 & 89.2 & 89.4 & 89.6 & 1.3 & 0.3 & -0.5 & $18 \%$ \\
\hline France & Male & 85.2 & 86.2 & 87.1 & 88.2 & 89.1 & 89.8 & 3.0 & 2.7 & 2.7 & $84 \%$ \\
\hline TGHF05 & Female & 90.1 & 91.3 & 92.4 & 91.7 & 92.5 & 93.3 & 1.6 & 1.2 & 0.9 & $70 \%$ \\
\hline Germ & Male & 84.2 & 85.3 & 86.2 & 86.7 & 87.3 & 87.8 & 2.5 & 2.0 & 1.6 & $55 \%$ \\
\hline DAV2004R & Female & 87.8 & 89.1 & 90.1 & 90.4 & 91.1 & 91.6 & 2.6 & 2.0 & 1.5 & $52 \%$ \\
\hline Israel & Male & 86.2 & 87.3 & 88.2 & 86.6 & 87.0 & 87.3 & 0.4 & -0.3 & -0.9 & $35 \%$ \\
\hline EMSSA09 & Female & 88.7 & 90.0 & 91.0 & 89.2 & 89.5 & 89.7 & 0.5 & -0.5 & -1.3 & $22 \%$ \\
\hline Japan & Male & 86.0 & 87.1 & 88.1 & 87.9 & 87.9 & 87.9 & 1.9 & 0.8 & -0.2 & $0 \%$ \\
\hline SMT07 & Female & 92.2 & 93.4 & 94.5 & 94.7 & 94.7 & 94.7 & 2.5 & 1.3 & 0.2 & $0 \%$ \\
\hline Netherlands & Male & 84.6 & 85.7 & 86.6 & 84.4 & 85.3 & 85.8 & -0.2 & -0.4 & -0.8 & $70 \%$ \\
\hline AGP10 & Fem & 88.0 & 89.2 & 90.3 & 87.4 & 87.9 & 88.2 & -0.6 & -1.3 & -2.1 & $35 \%$ \\
\hline Spain & Male & 85.2 & 86.3 & 87.2 & 85.1 & 85.7 & 86.1 & -0.1 & -0.6 & -1.1 & $50 \%$ \\
\hline PERMFC00 & Female & 89.8 & 91.1 & 92.2 & 89.5 & 90.0 & 90.5 & -0.4 & -1.1 & -1.7 & $42 \%$ \\
\hline Switzerland & Male & 85.9 & 87.0 & 88.0 & 88.6 & 89.7 & 90.7 & 2.7 & 2.7 & 2.7 & $100 \%$ \\
\hline ERMF09 & Female & 89.4 & 90.6 & 91.7 & 91.2 & 92.1 & 92.9 & 1.8 & 1.5 & 1.2 & $74 \%$ \\
\hline USA & Male & 84.5 & 85.5 & 86.4 & 85.0 & 85.5 & 85.8 & 0.5 & 0.0 & -0.5 & $42 \%$ \\
\hline GAM94-AA & Female & 87.6 & 88.8 & 89.7 & 87.5 & 87.8 & 88.0 & -0.1 & -1.0 & -1.7 & $24 \%$ \\
\hline
\end{tabular}

Table 1. Expected lifespan of people aged 65 in 2009, 2015 and 2020: computed on the best practice trend approach for general populations and on commonly used actuarial tables insured population, for males and females of various countries. It would be expected that insured people live longer than the general population: when this is not the case, the difference is highlighted in gray. It is highlighted in light gray when the difference is particularly low (less than 3 years for males and less than 1 year for females). The last column compares the longevity improvements of the actuarial table with those of the best practice trend: $\left(e_{g 65}^{2020}-e_{g 65}^{2009}\right)_{\text {actuarial table }} /\left(e_{g 65}^{2020}-\right.$

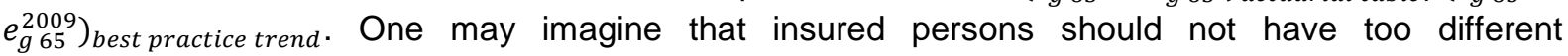
improvements from the general population, i.e. that the indicator should not be too different from $100 \%$. We have therefore grayed the indicator when it is lower than $70 \%$ (arbitrary value).

We could precisely compute some risks in terms of potentially insufficient reserves for the different countries, but this would require estimating the degree of prudence of current mortality rates for each table. We rather do such an analysis below for the sole case of France, in presence of extreme longevity scenarios. 


\section{DEALING WITH THE RISK OF EXTREME LONGEVITY}

\subsection{LONGEVITY RISK WITH REGARDS TO OTHER SCENARIOS OF FUTURE LONGEVITY}

Figure 3 focused on comparing commonly used assumptions with linear increases of life expectancy. There are however obviously a whole range of possible scenarios of future life expectancy as highlighted in Figure 8. It illustrates that trends of commonly used actuarial assumptions are actually not so different from linear extrapolations of life expectancy when compared with very different potential trends.
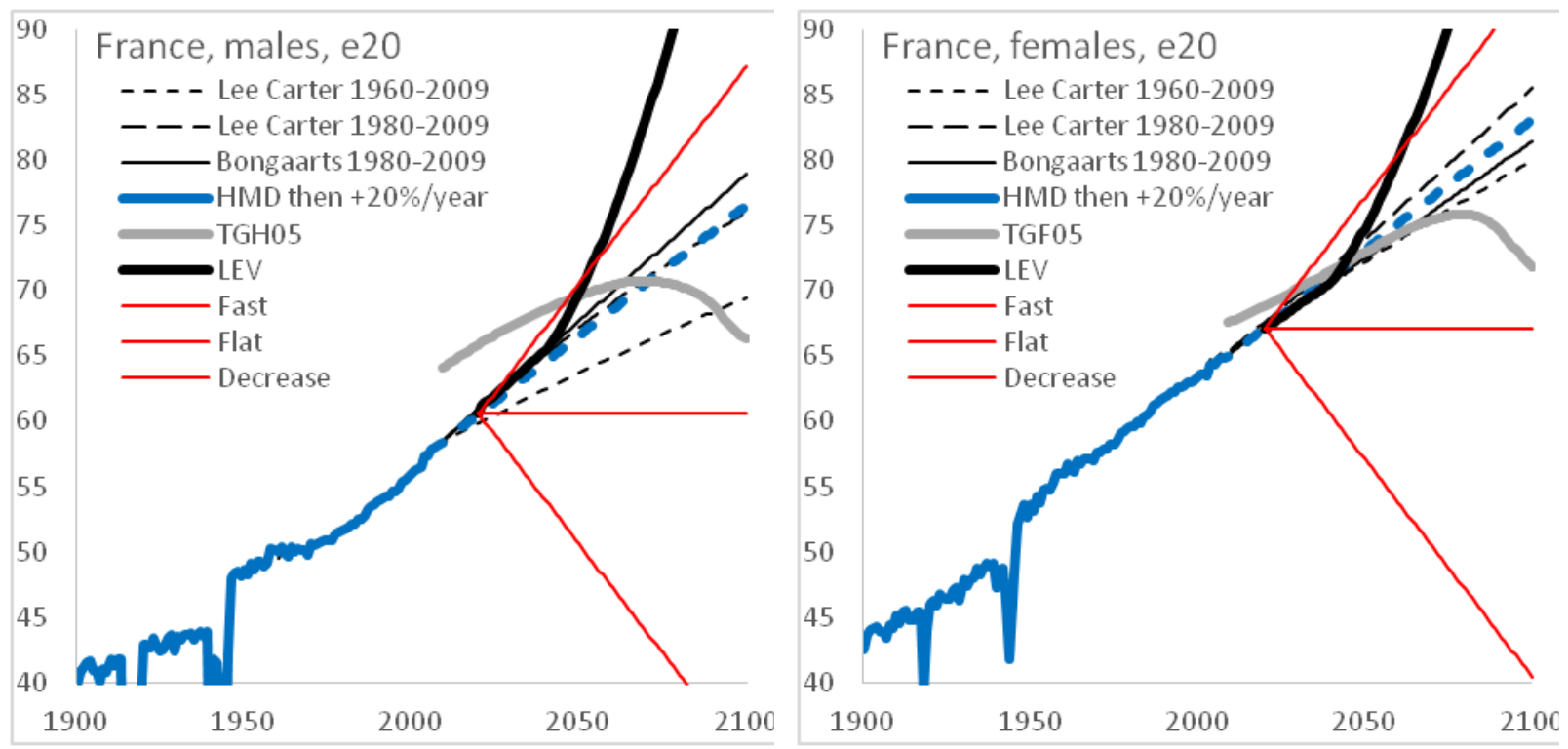

Figure 8. Historical as well as projected life expectancy at age $\mathbf{2 0}$ for French males (left) and females (right). It includes contents from Figure 2 i.e. historical values and Best Practice Trend ("+20\%/year", thick line), regulatory prospective tables (here TGH/F05, gray decelerating thick line), Lee Carter models (dashed lines) and Bongaarts model (solid line close to "+20\%/year). It also represents more extreme scenarios: a decrease of life expectancy at the pace of 4 months per year ("Decrease", decreasing straight line), a stable life expectancy ("Flat", horizontal line), an increase of life expectancy at the pace of 4 months per year ("Fast", increasing straight line), and an accelerating life expectancy ("LEV" for Longevity Escape Velocity, thick black line).

In order to compute corresponding financial risk estimates we not only need to deal with longevity trends but also with the initial mortality level of actuarial tables. As a working hypothesis we consider that the [period] life expectancy at age 65 produced by actuarial tables in 2015, $e_{65,2015}$ is exact. In terms of trends for insured populations, we use the models we derived from the Bongaarts model and we adjust their mortality level (parameters ' $\mathrm{A}$ ' in section 2) to match the $e_{65,2015}$ of the table. The indicator of longevity risk is then the percentage of reserves that should be added if reserves were computed with that adjusted model instead of the actuarial table: $\frac{\ddot{a}_{65(B P T)}^{t}}{\vec{a}_{65(t a b l e)}^{t}}-1$, in absence of interest rate and inflation risk. The results are shown in Table 2. Of course, the effect is more important in a long interest rate context and financial risks are important factors that we do not consider here. 
E. Debonneuil, S. Loisel, F. Planchet

\begin{tabular}{|c|c|c|c|c|}
\hline For people aged 65 & $\ln 2015$ & & $\ln 2025$ & \\
\hline Trend/ Scenario & Males & Females & Males & Females \\
\hline LEV & $+4.3 \%$ & $+6.5 \%$ & $+13.6 \%$ & $+9.8 \%$ \\
\hline Fast & $+3.6 \%$ & $+5.4 \%$ & $+7.7 \%$ & $+6.2 \%$ \\
\hline Bongaarts & $+1.9 \%$ & $+1.4 \%$ & $+4.0 \%$ & $-6.0 \%$ \\
\hline Best Practice Trend & $+0.6 \%$ & $+2.5 \%$ & $+0.7 \%$ & $-1.5 \%$ \\
\hline Actuarial Table & $0 \%$ & $0 \%$ & $0 \%$ & $0 \%$ \\
\hline Flat & $-8.0 \%$ & $-7.5 \%$ & $-8.1 \%$ & $-11.1 \%$ \\
\hline Decrease & $-18.7 \%$ & $-19.5 \%$ & $-18.9 \%$ & $-22.7 \%$ \\
\hline
\end{tabular}

Table 2. Impact on reserves when modifying the trend of existing actuarial tables

Table 2 gives an order of magnitude of the financial risk. In practice the true financial risk might not be well characterized by a single number. If the present value of losses compared to existing reserves were considered for a current portfolio it could be greater or lower depending on the considered retirement system and therefore ages to be considered, on absorption mechanisms, and in particular on the presence of guaranteed tables or not (the latter being obviously problematic if scenarios like Fast or LEV were to take place in the future). Besides such important considerations, Table 2 reveals that if life expectancy increased at the same rate as in the past the financial impact would be moderate (less than $2 \%$ impact on reserves for people aged 65 in 2015) and that more diverse scenarios can have more severe impacts. Regarding the Fast and LEV scenarios, the impacts are much stronger ten years ahead than today.

It is certainly easier for retirement systems to adapt to lower than to higher life expectancy than planned. Therefore, high life expectancy scenarios such as the "Fast" and "LEV" scenarios should be considered with care, especially as they differ from currently used tables or even from the Best Practice Trend in a substantial manner: if they were credible then it would be adequate that the long term nature of retirement liabilities leads society to preemptively build solutions to face such scenarios in a serene manner. On the other hand, using them blindly could lead to inappropriate conclusion regarding pension funds solvency. As an attempt to help judge the credibility of such scenarios, given that LEV scenarios are mentioned by bio gerontologists and given that bio gerontologists and actuarial scientists do not generally naturally work together, we further try to gather and investigate concrete advances in biogerontology.

\subsection{HOW SERIOUS IS BIOGERONTOLOGY ABOUT STRONG LIFE EXTENSIONS?}

Biogerontology can be defined as the science that studies aging from a biological perspective. The following text attempts to briefly gather biomedical advances and views that can be found in biogerontology circles such as in the specialized mailing-list Gerontology Research Group or the International Longevity Alliance (group of biogerontology associations from more than 50 countries).

First, as an attempt to briefly explain views, increasing in life expectancy can be schematized in two phases. The first phase has mostly dealt with microbes and the second phase deals with biological aging.

i) The action of Louis Pasteur is typical of the first phase: convincing the world that microbes are everywhere, even if invisible, and that they can be avoided or treated through various techniques. Some of those techniques are hygiene (e.g.: boiling water, washing hands, the development of refrigerators and cold chains), vaccines and antibiotics. As noted by Vaupel (2010) such techniques have contributed to a drop of infant and young adult mortality rates. 
ii) Currently biomedical actions of society are typical of the second phase: convincing the world that the pathologies that we get as we grow older can be avoided and treated, at least to some extent, through various techniques. This includes advances against cancer, cardiovascular diseases, stroke, and dementia. It goes beyond as the increased rate of such diseases with age as when as frailty is believed to set from common processes and accumulation of deteriorations that can be mitigated with lifestyles including regular physical activity, drugs, genetic therapies and regenerative medicine. It is believed that the unprecedented awareness about the topic, exploration of first results, increased communication across researchers and the rapid development of stem cell, organ generation, health information technology and other technologies will help lead to a drop of mortality rates at late adulthood within a few decades.

Secondly, here are some concrete results to help judge current progress.

Due to one gene change, some naturally-dwarf mice ('Ames dwarf mice') were found to live about 50\% longer than their siblings and their lifespan is further increased with some specific lifestyle known as 'caloric restriction' (Bartke, 2008). Equivalently mutated people are naturally found, known as 'Laron dwarfs', who seem to be resistant to diabetes and cancer; they are generally rejected from society which so far doesn't allow to possibly measure longer lives (Guevara-Aguirre, 2011). It has not yet been tested whether performing the mutation once mice are adults extends their lifespan; if so, human applications would possibly not be far.

Several human drugs were showed to prolong the life - and healthy life - of adult mice by $6 \%$ to $26 \%$ when given chronically and at low doses; such as aspirin (Strong 2008), metformin (Martin-Montalvo, 2013), rapamycin (Harrison 2009, Ye 2013). The latter has included successful results when starting at a late age and a projects are starting to test rapamycin versus placebo in dogs and various companion animals (Check Hayden 2014, Kaeberlein 2015). Since people generally do not currently take treatments when not ill equivalent results are difficult to find in existing human data. However, some relatively close circumstances indicate that those drugs - low dose aspirin (Cuzick 2014), metformin (Bannister 2014), rapamycin (has since become a first-line treatment in oncology), everolimus (Mannick JB 2014) - are also generally beneficial with respect to human health as we grow older. In 2015, a clinical trial is started to test on one thousand non-diabetic people whether metformin is globally beneficial (TAME study, Albert Einstein College of Medicine).

As gene therapy in adult individuals starts to become safe, and possibly have better benefit-risk balances than drugs, a 'telomerase' gene therapy was performed in adult mice and increased their lifespan by $13 \%$ to $24 \%$ depending on the age at start (Bernardes de Jesus 2012). In April 2015, in a Mexican hospital and a Colombian hospital, renowned scientists of that field have started to commercialize a similar human 'telomerase' gene therapy as well as another gene therapy that helps, according to them, muscles grow in spite of advancing in age (Mitteldorf, 2015). One of those scientists has tested the latter on himself in 2010.

Non-drug, non-genetic interventions are being put in place too. Recently, a renowned scientist published that he grew a new thymus on himself, after the method was developed in rats and for AIDS patients (Fahy, 2003). The thymus is an organ that develops our immune system and that shrinks at adulthood. A company, Intervene 
Immune, has since been started to treat other persons similarly, the hope being to typically better protect from viruses and cancer.

On the quest to tackle underlying joint solutions to age-related frailty and various agerelated diseases, progress is moving from small-scale companies to pharmaceutical companies such as the Calico company created by Google, Human Longevity, Navitor Pharmaceuticals or others (McGreevey 2015). Attempts are being done to officially define aging as a disease in order for such research to find corresponding funds for the pharmaceutical industry and for treatments to be covered by health insurance (Hayden 2015, Zhavoronkov and Bhullar 2015, Bulterijs et al. 2015, Gems 2013).

At the individual level forecasts are not to increase long term needs but rather to help the body repair, regrow, restore and maintain vitality; at collective level consequences are debated such as risks of overpopulation or unequal access to corresponding healthcare (Alexandre 2011, Coeurnelle 2013). As a result, for both technological and social reasons it is difficult to judge in what timeframe results would extend the lifespan of populations. They seem however sufficiently massive by people in the field to be more important than the forces that would instead tend to decelerate longevity, and to be worth communicating to actuaries that a best estimate scenario could rather be that life expectancy accelerates in the future.

We shall remind that considering such views is important for retirement systems in the sense that it allows to prepare for such cases but that various other views exist including the possibility to reach a maximum life expectancy ceiling or even to see life expectancy decrease (Aubert et al., 2010; Cambois et al., 2010; Debonneuil et al. 2011).

\subsection{HOW DO GOVERNMENTS POSITION THEMSELVES?}

The authors of this paper live in France and have therefore searched for assumptions used by French public authorities. The longevity trends used by French public instances (the "Conseil d'Orientation des Retraites", COR) to define adjustments in the public retirement systems are significantly lower than the standard French actuarial tables TGH TGF 2005 (Table 3).

\begin{tabular}{|l|l|l|l|l|l|l|}
\hline \multirow{2}{*}{ Example: France } & \multicolumn{3}{|l|}{ e60,2010 } & \multicolumn{2}{l|}{ e60,2060 } & \multicolumn{2}{l|}{ Difference } \\
\cline { 2 - 8 } & Males & Females & Males & Females & Males & Females \\
\hline LC 1980-2009 & 22.6 & 27.6 & 31.0 & 37.5 & 8.4 & 9.9 \\
\hline Best Practice Trend & 21.5 & 27.0 & 29.8 & 36.3 & $\mathbf{8 . 3}$ & $\mathbf{9 . 3}$ \\
\hline TGH TGF 2005 & 25.8 & 29.1 & 32.3 & 35.6 & $\mathbf{6 . 5}$ & $\mathbf{6 . 5}$ \\
\hline LC 1960-2009 & 22.5 & 27.5 & 27.7 & 35.0 & 5.2 & 7.5 \\
\hline COR & 22.2 & 27.2 & 28.0 & 32.3 & $\mathbf{5 . 8}$ & $\mathbf{5 . 1}$ \\
\hline LC 1960-1989 & 21.1 & 27.1 & 26.1 & 32.3 & 5.0 & 5.2 \\
\hline
\end{tabular}

Table 3. Life expectancy at age 60 and its increase between 2010 and 2060 according to assumptions used by the Conseil d'Orientation des Retraites (COR) (COR, 2013) and according to other assumptions in France (Lee-Carter model fitted on different periods, regulatory tables for insured TGH TGF 2005 and Best Practice Trend model). The increase in life expectancy of the COR assumption is in particular significantly lower than that of the regulatory tables (last 2 columns).

We have not investigated if government instances of other countries also use assumptions that have lower life expectancy trends than the country-specific commonly used actuarial tables. Certainly, dealing with complex social systems adjustments (such as pressure not to increase retirement age by much) makes it difficult to take prudent assumptions. This is in fact a sensitive political issue, where myopic view often favors short-term effects and postpones discussions about inter-generational risk transfers. 


\subsection{MORE PRUDENT TABLES TO ENVISION SOLUTIONS}

Mortality projections are elements that help adjust retirement systems. Mentioning more prudent mortality assumptions, such as using the Best Practice Trend, the "Fast" or the "LEV" scenarios at least to envision the behavior of existing systems, may help be aware of non-decelerating life expectancy potentials impacts, and not think that volatility is limited to the one of the noise in Lee-Carter type models. Typically it may further reduce the use of guaranteed tables may. It may also help consider structural changes that may be globally better in a vast range of future scenarios.

For example, it may be possible to apply methods on such scenarios that statistically detect that mortality rates do not follow expectations (see Croix et al. 2015 and El Karoui, Loisel and Salhi 2015) of new trends and to estimate how longevity risk was mitigated if then retirement age was increased at a given realistic pace. If longevity risk was not mitigated enough, then retirement age should be preemptively increased. The latter was already suggested without such technique (Zhavoronkov et al., 2012; Zhavoronkov, 2013). Such approaches could now help build quantified analysis for more concrete discussions.

A general increase of retirement age is of course only one of many levers. Using such scenarios may help study other approaches. While presenting perspectives of linear increases in life expectancy, James Vaupel for example used such perspectives to estimate that working less per week in exchange of working more years might be some appealing solution (Vaupel, 2010).

Not all boils down to actuarial assumptions. In the latter investigation, working less per week may for example mean working one day less per week, earn less as well and be encouraged to use the extra day for familial activities (taking care of children or parents) or new economic activities but it may as well lead to distortions of competitions and relocation of businesses. However, citizen behaviors may also be studied based on similar situations (Forget, 2011). In contrast, today's longevity-decelerating scenarios seem unlikely to help be ready in case of accelerations of life expectancy.

\subsection{FINANCIAL HEDGES TO HELP MITIGATE LONGEVITY RISK}

In addition to reviewing the sufficiency of commonly used actuarial tables much literature suggests that governments establish solutions to hedge longevity risk (Antolin and Blommestein 2007, Antolin and Mosher 2014, Blake et a. 2014).

Substantial work has been produced to price longevity risk and to propose financial tools such as bonds and swaps to transfer the risk to specific stakeholders or even capital markets (Barrieu et al. 2012, Bauer et al. 2010, Barbarin 2008, Blake et al. 2006, Coughlan et al. 2011, Hunt and Blake 2015, Kogure and Kurachi 2010, Lane 2011, Ngai and Sherris 2011, Olivieri and Pitacco 2008, Wan and Bertschi 2015).

Some natural hedge may be found by associating longevity risk with mortality risk. Product design (Richter A and Weber 2011), reverse mortgages (Wang et al. 2011) and protection insurance (Cox and Lin, 2007) may provide some longevity hedge. The natural hedge remains however partial (Zhu and Bauer 2014).

There might be opportunities to invest in assets that are very different from mortgages or insurance and that make profits with longevity increases. If biogerontology scenarios investigated here can happen, it might be better for retirement funds to invest into such 
developments and manage longevity profits rather than suffer from such scenarios (Fagnan et al. 2013, Fernandez et al. 2012, MacMinn et al. 2015, Yang et al. 2016).

\section{Discussion}

We have highlighted that commonly used actuarial assumptions tend to produce life expectancy deceleration and found underlying mathematical explanations as well as elements that suggest that governments may be unwilling to consider non-decelerating longevity assumptions, thereby putting retirement systems at risk.

We have developed some models that produce non-decelerating life expectancies. With the increasing prospects of strong increases in human lifespan, for example through the arguably promising field of biogerontology, such models may help be prepared in case biogerontology promises come true. Considering advances in biogerontology and associated scenarios may help find solutions; detecting changes early enough to act or even investing into biogerontology companies might even be parts of solutions, even if it necessarily takes very long, often too long before one may react on a firm statistical background.

In a few decades, it may well be that a pandemic, resistance to antibiotics, a war, social instability or individuals preferring a reasonably long, happy life to a very long life with a lot of invasive monitoring, or some other event, causes longevity improvements to decline or vanish, and that our descendants laugh at us and at our crazy concerns about longevity risk.

It might also happen that longevity improvements develop further, and that biogerontology science finally impacts strongly life expectancy. In that case, our descendants would blame us for not anticipating this scenario early enough, and according to the most optimistic gerontologists, we might even sit in the court in person if we are still alive then!

There is currently no evidence that this science will produce results in the near future. The authors of this paper have different views, either believing in longevity acceleration and deceleration. However, the authors share the conclusion that the different scenarios should be presented and considered by decision makers, like climate change scenarios investigated by GIEC.

It would be inappropriate and impossible to adopt the LEV scenario as the new best estimate oof course. But it is important to make governments, politicians and risk managers of insurance companies, pension funds, reinsurance companies and banks aware that the uncertainty on future longevity developments is much greater than the volatility accounted for in the Lee-Carter model and its subsequently developed models. Understanding and managing this risk requires an interdisciplinary approach.

Given the potential size of the risk we support the conclusion of Antolin and Mosher (2014), who suggest that governments further investigate how to make retirement systems resilient to such scenarios.

\section{ACKNOWLEDGEMENT}

We thank Alexander Zhavoronkov for discussions on refreshing solutions for retirement systems. We are grateful to active leading members of the International Longevity 
Alliance for having reviewed the section on biology of aging: Didier Coeurnelle, Anton Kulaga, Daria Khaltourina, Elena Milova, Liz Parrish, Avi Roy, Paul Spiegel, Daniel Wuttke.

Acknowledgment. This work benefited from the financial support of the ANR project "LoLitA" (ANR-13-BS01-0011), research chair "Management de la modélisation" sponsored by Cardif, and research chair "Actuariat Durable" sponsored by Milliman Paris.

\section{REFERENCES}

Alexandre L (2011): La mort de la mort. Editions JC Lattès

Antolin P and Blommestein H (2007): Governments and the Market for Longevity-Indexed Bonds. Organisation for Economic Cooperation and Development Working Papers on Insurance and Private Pensions, No. 4, OECD Publishing, Paris.

Antolin P and Mosher J (2014): Mortality Assumptions and Longevity Risk. Working Party on Private Pensions.

Arnold S, Boumezoued A, Labit Hardy H, El Karoui N (2015): Cause-of-Death mortality: What Can Be Learned From Population Dynamics? <hal-01157900>

Bannister CA, Holden SE, Jenkins-Jones S, Morgan CL, Halcox JP, Schernthaner G, Mukherjee J, Currie CJ (2014): Can people with type 2 diabetes live longer than those without? A comparison of mortality in people initiated with metformin or sulphonylurea monotherapy and matched, non-diabetic controls. Diabetes Obes Metab.

Barbarin J (2008): Heath-Jarrow-Morton Modelling of Longevity Bonds and the Risk Minimization of Life Insurance Portfolios, Insurance: Mathematics and Economics, 43: 4155 .

Barrieu P, Bensusan H, El Karoui N, Hillairet C, Loisel S, Ravanelli C and Salhi Y (2012): Understanding, Modeling and Managing Longevity Risk: Key Issues and Main Challenges. Scandinavian Actuarial Journal, 3: 203-231.

Bartke A, Bonkowski M, Masternak M. (2008): How diet interacts with longevity genes. Hormones, 7:17-23. Review.

Bauer D, Börger $M$ and Ruß J (2010): On the Pricing of Longevity-Linked Securities. Insurance: Mathematics and Economics, 46:139-149.

Beard JR, Biggs S, Bloom DE, Fried LP, Hogan P, Kalache A, Olshansky SJ (2011): Global Population Ageing: Peril or Promise? World Economic Forum.

Bernardes de Jesus B, Vera E, Schneeberger K, Tejera AM, Ayuso E, Bosch F, Blasco MA. (2012): Telomerase gene therapy in adult and old mice delays aging and increases longevity without increasing cancer. EMBO Mol Med. 4:691-704

Bongaarts J (2014): Long-Range Trends in Adult Mortality: Models and Projections Methods. Population Council, WP192.

Blake D, Boardman T and Cairns A (2014): Sharing Longevity Risk: Why Governments Should Issue Longevity Bonds. North American Actuarial Journal, 18(1): 258-277.

Blake D, Cairns AJG, Dowd K and MacMinn R (2006): Longevity Bonds: Financial Engineering, Valuation and Hedging. Journal of Risk and Insurance, 73: 647-72. 
Brouhns N, Denuit M, Vermunt J (2002): A Poisson log-bilinear regression approach to the construction of projected lifetables. Insurance: Mathematics and Economics 31; 373-393.

Bulterijs S, Hull RS, Bjork VC and Roy AG (2015): It is time to classify biological aging as a disease. Front Genet 6, 205

Cairns A, Blake D, Dowd K, Coughlan GD, Epstein D and Khalaf-Allah M (2011): Mortality density forecasts: An analysis of six stochastic mortality models. Insurance: Mathematics and Economics 48; 355-367

Cairns A, Blake D, Dowd K, Coughlan GD, Epstein D, Ong A and Balevich I (2007): A Quantitative comparison of stochastic mortality models using data from England and Wales and the United States.

Cairns A, Blake D, Dowd K, Kallestrup-Lamb, Rosenskjold (2015): Multi-population modelling: a Danish case study. Talk at the Longevity 11 conference.

Check Hayden E (2014): Pet dogs set to test anti-ageing drug. Nature 514(7524)

Coeurnelle D (2013): Et si on arrêtait de vieillir! : Réalité, enjeux et perspectives d'une vie en bonne santé beaucoup plus longue. Editions FYP

Conseil d'Orientation des Retraites (2013): Retraites: perspectives 2020, 2040 et 2060.

Coughlan GD, Khalaf-Allah M, Ye Y, Kumar S, Cairns AJG, Blake D and Dowd K (2011): Longevity Hedging 101: A Framework for Longevity Basis Risk Analysis and Hedge Effectiveness. North American Actuarial Journal, 15: 150-176.

Cox SH, and Lin Y (2007): Natural Hedging of Life and Annuity Mortality Risks. North American Actuarial Journal, 11: 1-15.

Croix JC, Planchet F, Thérond PE (2015): Mortality : a statistical approach to detect model misspecification. Bulletin Français d'Actuariat

Cuzick J, Thorat MA, Bosetti C, Brown PH, Burn J, Cook NR, Ford LG, Jacobs EJ, Jankowski JA, La Vecchia C, Law M, Meyskens F, Rothwell PM, Senn HJ, Umar A (2014): Estimates of benefits and harms of prophylactic use of aspirin in the general population. Ann Oncol.

Debonneuil E, He L, Mosher J, Weiss N (2011): Longevity Risk: Setting the scene. Riskbooks

Dublin LI (1928): Health and Wealth. A Survey of the Economics of World Health (Harper, New York), page 361

Fagnan DE, Fernandez JM, Lo AW, Stein RM (2013): Can financial engineering cure cancer? The American Economic Review; 103:406-411

Fahy GM (2003): Apparent induction of partial thymic regeneration in a normal human subject: a case report. J Anti-Aging Med; 6 (3):219-227

Fernandez JM, Stein RM, Lo AW (2012): Commercializing biomedical research through securitization techniques. Nature biotechnology; 30:964-975.

Forget EL (2011): The Town with No Poverty: The Health Effects of a Canadian Guaranteed Annual Income Field Experiment. Canadian Public Policy; 37 (3)

Gems D (2014): What is an anti-aging treatment? Experimental Gerontology 58; $14-18$ 
de Grey ADNJ (2015): Ask Aubrey de Grey Anything! Reddit online exchange. https://www.reddit.com/r/Futurology/comments/3fri9a/ask aubrey de grey anything

de Grey ADNJ (2004): Escape Velocity: Why the Prospect of Extreme Human Life Extension Matters Now. PLoS Biol 2(6): 723-726

Guevara-Aguirre, J; Balasubramanian, P; Guevara-Aguirre, M; Wei, M; Madia, F; Cheng, CW; Hwang, D; Martin-Montalvo, A et al. (2011): "Growth Hormone Receptor Deficiency Is Associated with a Major Reduction in Pro-Aging Signaling, Cancer, and Diabetes in Humans". Science Translational Medicine 3 (70): 70ra13. doi:10.1126/scitranslmed.3001845. PMC 3357623. PMID 21325617.

Harrison DE, Strong R, Sharp ZD, Nelson JF, Astle CM, Flurkey K, Nadon NL, Wilkinson JE, Frenkel K, Carter CS, Pahor M, Javors MA, Fernandez E, Miller RA (2009): Rapamycin fed late in life extends lifespan in genetically heterogeneous mice. Nature 460(7253), 392-5.

Hayden EC (2015): Anti-ageing pill pushed as bona fide drug. Regulators asked to consider ageing as a treatable condition. Nature 522, 265-266

Human Mortality Database. University of California, Berkeley (USA), and Max Planck Institute for Demographic Research (Germany). Available at www.mortality.org (data downloaded on April 20 ${ }^{\text {th }}$ 2015).

Hunt A, and Blake D (2015): Modelling Longevity Bonds: Analysing the Swiss Re Kortis Bond. Insurance: Mathematics and Economics, 63, 12-29.

Kaeberlein M (2015): The Biology of Aging: Citizen Scientists and Their Pets as a Bridge Between Research on Model Organisms and Human Subjects. Vet Pathol

Kogure A and Kurachi Y (2010): A Bayesian Approach to Pricing Longevity Risk Based on Risk-Neutral Predictive Distributions. Insurance: Mathematics and Economics 46: 162-172.

Lane M (2011): Longevity Risk from the Perspective of the ILS Markets. Geneva Papers on Risk and Insurance - Issues and Practice, 36: 501-515.

Lee R and Carter L (1992): Modeling and Forecasting U.S. Mortality. Journal of the American Statistical Association. 87

Li N, Lee R, Gerland P (2013): Extending the Lee-carter method to model the rotation of age patterns of mortality decline for long-term projections. Demography. 50(6):2037-51. PMID: 23904392

Mannick JB, Del Giudice G, Lattanzi M, Valiante NM, Praestgaard J, Huang B, Lonetto MA, Maecker HT, Kovarik J, Carson S, Glass DJ, Klickstein LB (2014): mTOR inhibition improves immune function in the elderly. Sci Transl Med ; 6(268):268ra179. doi: 10.1126/scitranslmed.3009892.

Martin-Montalvo A, Mercken EM, Mitchell SJ, Palacios HH, Mote PL, Scheibye-Knudsen M, Gomes AP, Ward TM, Minor RK, Blouin MJ, Schwab M, Pollak M, Zhang Y, Yu Y, Becker KG, Bohr VA, Ingram DK, Sinclair DA, Wolf NS, Spindler SR, Bernier M, de Cabo R (2013): Metformin improves healthspan and lifespan in mice. Nat Commun 4, 2192.

Mitteldorf J (2015): Tomorrow's Anti-Aging Therapy, Available Today (BioViva). Josh Mitteldorf's Aging Blog. http://joshmitteldorf.scienceblog.com/2015/03/18/tomorrows-anti-agingtherapy-available-today/\#Bioviva (review) 
Ngai A and Sherris M (2011): Longevity Risk Management for Life and Variable Annuities: The Effectiveness of Static Hedging using Longevity Bonds and Derivatives. Insurance: Mathematics and Economics, 49: 100-114.

Oeppen J and Vaupel J (2002): Broken Limits to Life Expectancy. Science 296

Olivieri A and Pitacco E (2008): Assessing the Cost of Capital for Longevity Risk. Insurance: Mathematics and Economics, 42: 1013-1021.

Planchet F (2006): Tables de mortalité d'expérience pour les portefeuilles de rentiers (Tables TGH 05 et TGF 05). Note méthodologique de l'Institut des Actuaires.

Richter A and Weber F (2011): Mortality-Indexed Annuities: Managing Longevity Risk via Product Design. North American Actuarial Journal, 15: 212-236

Salhi Y, Loisel S (2012): Basis risk modelling: a co-integration based approach. <hal00746859>

Strong R, Miller RA, Astle CM, Floyd RA, Flurkey K, Hensley KL, Javors MA, Leeuwenburgh C, Nelson JF, Ongini E, Nadon NL, Warner HR, Harrison DE (2008): Nordihydroguaiaretic acid and aspirin increase lifespan of genetically heterogeneous male mice. Aging Cell. 7(5): 641-650.

Vallin J et Meslé F (2010): Espérance de vie: peut-on gagner trois mois par an indéfiniment ? Population \& Sociétés 473

Vaupel JW (2010): Biodemography of human ageing. Nature 464, 536-542

World Health Organization (2015): World Health Statistics 2015

Ye L, Widlund AL, Sims CA, Lamming DW, Guan Y, Davis JG, Sabatini DM, Harrison DE, Vang O, Baur JA (2013): Rapamycin doses sufficient to extend lifespan do not compromise muscle mitochondrial content or endurance. Aging 5(7), 539-50.

Wan C and Bertschi L (2015): Swiss Coherent Mortality Model as a Basis for Developing Longevity De-Risking Solutions for Swiss Pension Funds: A Practical Approach. Insurance: Mathematics and Economics, 63: 66-75.

Wang JL, Hsieh M and Chiu Y (2011): Using Reverse Mortgages to Hedge Longevity and Financial Risks for Life Insurers: A Generalized Immunization Approach. Geneva Papers on Risk and Insurance - Issues and Practice, 36: 697-717.

Yang X, Debonneuil E, Zhavoronkov A, Mishra B (2016): Cancer megafunds with in silico and in vitro validation: Accelerating cancer drug discovery via financial engineering without financial crisis. Oncotarget.

Zhavoronkov A, Debonneuil E, Mirza N, Artyuhov I (2012): Evaluating the impact of recent advances in biomedical sciences and the possible mortality decreases on the future of health care and Social Security in the United States. Pensions; 17, 241-251

Zhavoronkov A (2013): The Ageless Generation: How Advances in Biomedicine Will Transform the Global Economy. Palgrave Macmillan Trade

Zhavoronkov A, Bhullar B (2015): Classifying Aging as a Disease in the context of ICD-11. bioRxiv 